\title{
Cuerpos silenciados. El ingreso de restos humanos al Museo Etnográfico entre 1904 y 1916 durante las campañas militares al Gran Chaco argentino
}

Silenced bodies. The entry of human remains to the Etnhographic Museum between 1904 and 1916 during the military campaigns to the Argentine Gran Chaco

\section{Sandra Tolosa and Lena Dávila}

\section{(2) OpenEdition}

Journals

\section{Electronic version}

URL: http://journals.openedition.org/corpusarchivos/1529

DOI: 10.4000/corpusarchivos.1529

ISSN: 1853-8037

\section{Publisher}

Diego Escolar

\section{Electronic reference}

Sandra Tolosa y Lena Dávila, «Cuerpos silenciados. El ingreso de restos humanos al Museo Etnográfico entre 1904 y 1916 durante las campañas militares al Gran Chaco argentino », Corpus [En línea], Vol 6, No 1 | 2016, Publicado el 28 junio 2016, consultado el 19 abril 2019. URL : http:// journals.openedition.org/corpusarchivos/1529; DOI : 10.4000/corpusarchivos.1529

This text was automatically generated on 19 April 2019. 


\section{Cuerpos silenciados. El ingreso de restos humanos al Museo Etnográfico entre 1904 y 1916 durante las campañas militares al Gran Chaco argentino}

Silenced bodies. The entry of human remains to the Etnhographic Museum between 1904 and 1916 during the military campaigns to the Argentine Gran Chaco

\section{Sandra Tolosa and Lena Dávila}

Esa cabeza toba! Debéis verla. Si es la cabeza de un muerto, digo que hay en la muerte, como en la vida, algo que relampaguea. Lucio V. Mansilla ${ }^{1}$

\section{Introducción²}

1 El Museo Etnográfico, fundado en 1904 como museo universitario dependiente de la Facultad de Filosofía y Letras de la Universidad de Buenos Aires, se perfiló desde su creación más que como un espacio de exhibición, como un centro de enseñanza e investigación, financiado por el sistema universitario, de cara a la profesionalización disciplinar (Arenas 1989; Perazzi 2005). Esta finalidad científica colaboró con su prestigio, fomentado a través de las redes nacionales e internacionales que Juan Bautista Ambrosetti (1865-1917) tendió desde la institución, aprovechando su posición como miembro de los círculos de sociabilidad de elite de la época y recurriendo a sus propios vínculos personales dentro y fuera del espacio académico-científico. 
2 De un modo similar a otros directores, como Francisco P. Moreno para el Museo de La Plata, ${ }^{3}$ Ambrosetti se ocupó durante los primeros años de formar las colecciones de la institución, con el objetivo de utilizarlos como material de estudio, investigación o canje con otros espacios científicos. Sin embargo, en el caso de La Plata es importante mencionar que a este propósito se sumó el de la exhibición no solo de objetos sino también de restos humanos. Contrariamente, el Museo Etnográfico se destacó a lo largo de los años por no mostrar cráneos y esqueletos en vitrinas dispuestas para la observación del público visitante.

3 La prosecución del objetivo de sistematicidad seguido por Ambrosetti marcó una cierta diferencia con los científicos de su época, no obstante muchas otras similitudes. Esta caracterización sobre el director y la institución se sostuvo en la historiografía disciplinar a través del tiempo y en cierto modo lo "resguardó" de análisis demasiado críticos, en comparación con otros científicos de la época. De este modo, los aspectos más polémicos y ambiguos de su trayectoria han quedado inscriptos como parte de los "usos" de la época y no han sido examinados en profundidad.

4 A pesar de esto hay que destacar que los estudios específicos sobre el Museo Etnográfico son aún escasos y relativamente recientes. Estos han abordado centralmente la historia de las prácticas museológicas y, en menor medida, problemáticas concretas alrededor de colecciones particulares (Pérez Gollán y Pegoraro 2004, Gustavsson 2008, Pegoraro 2009; Pegoraro y Elias 2010, Pegoraro y Spolianski 2013). Partiendo de este joven marco de precedentes, nos interesa indagar acerca de un problema específico: la adquisición, durante los años iniciales del Museo, de una serie de restos mortales ${ }^{4}$ pertenecientes a indígenas contemporáneos a la época. La ambigüedad en la clasificación de estos cuerpos, incorporados a la Sección Antropológica del Museo - constituida en gran parte por restos "arqueológicos"- ya fue planteada por Gustavsson (2011). Coincidimos con la autora en que esta clasificación general pudo contribuir a invisibilizar las diferencias entre restos indígenas de diferentes épocas y que posiblemente esto haya colaborado con la escasa atención que ha tenido hasta ahora el problema que hoy planteamos.

5 Para abordarlo, nos hemos centrado en los restos mortales provenientes de la zona chaqueña durante las primeras décadas del siglo XX, ingresados al Museo en el marco más general de una serie de "misiones" y encargos realizados por el entonces director Juan B. Ambrosetti ${ }^{5}$ a personas residentes - tanto permanente como temporalmente- en diferentes puntos del territorio. Si bien las modalidades de pedido de materiales utilizadas por Ambrosetti involucraron a variadas personas e instituciones que pudieran servir a sus fines, el caso del Chaco constituye un problema particular, en tanto parte de los envíos al Museo - que actualmente forman parte de sus colecciones ${ }^{6}$ - fueron realizados por militares que participaban de las avanzadas territoriales contra los indígenas de esa zona. Por este motivo, nos interesa indagar a partir de la información de archivo existente, cómo Ambrosetti supo aprovechar la avanzada militar sobre el Gran $\mathrm{Chaco}^{7}$ a principios del siglo XX con el propósito de ampliar las colecciones etnográficas y antropológicas del Museo.

6 El paralelismo entre el envío de los objetos de los indígenas que Ambrosetti sentenciaba a una veloz desaparición y la concreta desarticulación de su resistencia a manos del Ejército es por demás observable. Mientras la cultura de los pueblos originarios era saqueada y destruida, la ciencia se erigía en un rol de "resguardo" de la misma, pero conservando solo sus fragmentos resignificados en vitrinas accesibles para el gusto y la instrucción de las clases medias y altas urbanas. Pero el aspecto más literal de esta paradoja entre 
destrucción y resguardo fue el ingreso, junto a los objetos etnográficos, de esqueletos y cráneos de indígenas de la región, algunos de los cuales fueron enviados por los miembros del propio Ejército que acorraló, diezmó y dominó a los pueblos originarios del Gran Chaco. Este marco permite profundizar en el vínculo de funcionalidad existente entre la ciencia y la guerra, muy referida en el caso del Museo de La Plata pero menos visible en el del Etnográfico.

7 En los apartados siguientes realizamos una breve contextualización de las estrategias utilizadas por Ambrosetti para abastecer al Museo Etnográfico y en particular para la creación de la Sección Antropológica. En este marco general, analizaremos algunos ejemplos concretos de pedidos de objetos y cuerpos a corresponsales territoriales, basándonos en la información de archivo existente. Luego contextualizaremos brevemente las principales campañas militares al territorio chaqueño y las relaciones trazadas entre la Facultad y el Ejército. Por último, mencionamos dos casos especialmente identificados en las fuentes: el del cráneo del cacique Carayá y el del esqueleto completo del cacique Illirí -y su hijo/a - cuyos restos habrían ingresado al Museo en la década de 1910. Respecto de este último aportaremos algunos datos que hemos podido relevar, con el objetivo de recuperar aspectos de su subjetividad, invisibilizados por su condición de "objeto" de estudio antropológico. Aun comprendiendo el contexto de la época en el que se insertaron estas prácticas institucionales de adquisición, el trabajo pretende aportar elementos a una reflexión actual sobre dichas prácticas y las consecuencias que tuvieron y tienen para los pueblos originarios, tanto en forma directa como en el imaginario social y académico.

\section{El Museo Etnográfico y sus estrategias de recolección}

8 El Museo Etnográfico de Buenos Aires fue fundado por decisión del decano de la Facultad de Filosofía y Letras Dr. Norberto Piñero y promovido por la insistencia y trabajo de su alma mater, Juan B. Ambrosetti, quien lo concibió como la primera institución sudamericana de su tipo, en el marco de la profesionalización e institucionalización de la enseñanza de los estudios arqueológicos, antropológicos y etnográficos, en forma independiente a las ciencias naturales donde antes se insertaban (Pegoraro 2005, Perazzi 2011).

9 El Museo se proponía dar cuenta de la naturaleza del hombre americano así como de la geografía y la cultura del resto de los continentes. A fin de poder cumplir con este propósito se organizaron tres secciones generales: Etnografía, Arqueología y Antropología. La primera tenía por objeto dar cuenta de la diversidad cultural, la segunda buscaba reconstruir el pasado del hombre americano, mientras que la última estaba destinada a la comparación de los rasgos físicos del hombre y de sus características "raciales" (Pegoraro 2005).

Como director del Museo - cargo que detentó hasta su muerte en 1917-, Ambrosetti inició la formación de las colecciones de la institución a partir de una ínfima colección inicial, que aumentó durante su mandato hasta alcanzar las 19.543 piezas en 1916, de acuerdo a la última Memoria anterior a su muerte. Su objetivo fue incorporar materiales específicamente destinados a su estudio, si bien en gran medida reprodujo prácticas vinculadas al coleccionismo, propias de la época. 
11 Las estrategias utilizadas para esa ampliación fueron diversas. En primer lugar, se realizaron expediciones financiadas por la Facultad de Filosofía y Letras, la mayoría de las cuales se centraron en los territorios del Noroeste Argentino, prosiguiendo la línea predilecta del director: la arqueología "calchaquí". En segundo lugar, Ambrosetti puso en marcha sus redes de vinculaciones personales, sustentadas en su posición y prestigio socio-profesional, a partir de las cuales promovió donaciones de particulares, intercambió materiales con otras instituciones y se contactó con distintos comercializadores de piezas. Por último, estableció misiones especiales y corresponsalías en el interior del país. Esta modalidad facilitaba el acceso a los territorios evitando el trabajo de organización y el gasto económico que implicaba una expedición, al mismo tiempo que se aprovechaban los conocimientos y relaciones de los residentes locales. Los avances en el aumento de las colecciones a través de estas modalidades se explicitaban anualmente en las Memorias elevadas al decano de la Facultad.

Es particularmente entre 1909 y 1916 que asistimos a una especie de "fiebre coleccionista", en tanto la actividad y el número de objetos del Museo aumentaron exponencialmente. En este contexto, uno de los objetivos fue la ampliación de las colecciones etnográficas. Hay que tener en cuenta que para el año 1907 esa sección era aún muy pequeña: 41 objetos, entre las donaciones y los 16 recogidos en expediciones, en contraposición a las 2.380 piezas existentes en la sección arqueológica, diferencia que imposibilitaba cumplir completamente los objetivos de la institución (Pegoraro 2009, p. 55). En esta búsqueda, el horizonte territorial de Ambrosetti se amplió hacia los espacios recientemente "integrados" a la soberanía estatal por medio del avance político-militar: los Territorios Nacionales. El acercamiento a estas nuevas regiones se realizó a través de las vías de colaboración ya mencionadas y de relaciones institucionales específicas. Así lo comunicaba la Memoria de ese año, elevada al entonces decano Rodolfo Rivarola:

También se ha aportado un buen material con el resultado de las diversas expediciones y misiones especiales encomendadas a diversas personas amigas del Museo entre las que hay que citar la del Señor Eduardo A. Holmberg (hijo), Señor Enrique Lynch Arribálzaga, Señor Luis González Leiva, Francisco Cubas y Eugenio J. Leroux, quienes han continuado sus envíos desde los Territorios Nacionales del Chaco, Formosa, Chubut y Santa Cruz. ${ }^{8}$

Para hacerse comprender en contextos disímiles y ausentes de "especialistas", Ambrosetti utilizó como principal herramienta las "instrucciones", elaboradas con el fin de preservar el cuidado y buen tratamiento del material durante las fases de recolección, guardado y transporte. Dicha herramienta era fundamental para que los académicos del centro pudieran implantar en los espacios más capilares del territorio ciertas pautas de sistematicidad, una gran preocupación para Ambrosetti, quien insistía en la importancia de lograr precisión en los registros de los objetos recolectados de modo que no perdieran valor científico. En consecuencia, Ambrosetti dio curso a una serie amplia de pedidos con instrucciones ad hoc, dirigidos a sujetos diversos, en los cuales detallaba los objetos en que la institución estaba interesada. Todas las piezas eran consideradas preciadas, ya que o bien se utilizaban para ampliar las colecciones o bien para canjear con otras instituciones, por ejemplo en el caso de los objetos duplicados. ${ }^{9}$

Bajo esta modalidad, un caso relevante de acceso a los Territorios Nacionales fue posibilitado por el apoyo personal que le brindara a Ambrosetti Isidoro Ruiz Moreno, en ese momento a cargo de esa Dirección. En carta del 22 de julio de $1915^{10}$ Ambrosetti agradecía la buena voluntad de Ruiz Moreno y le adjuntaba "las listas é instrucciones para la remisión de los objetos que nos hacen falta para completar nuestras colecciones 
etnográficas y arqueológicas de los Territorios Nacionales". La Dirección reenvió las mismas a través de una circular a las gobernaciones y desde allí a los comisarios de policía departamentales, a fin de que "investigasen, entre los pobladores de su jurisdicción, la existencia de los objetos que el Museo Etnográfico desea adquirir, por ser estos empleados los que más exactas noticias pueden suministrar por su conocimiento y relaciones con los habitantes de los departamentos". ${ }^{11}$ El registro existente indica que la circular y la lista de objetos adjunta fueron enviadas a las gobernaciones de Misiones, Santa Cruz y Chaco, ${ }^{12}$ aunque con resultados poco alentadores, como se desprende de la casi ausencia de respuesta de las dos últimas y de las numerosas pero negativas contestaciones enviadas desde Misiones.

Es importante señalar aquí dos cuestiones. En primer lugar, la relevancia que cobraban los vínculos personales -en este caso entre Ambrosetti y Ruiz Moreno- como vehiculizadores de los pedidos de una institución estatal a otra. De un modo corriente en la época, el funcionamiento institucional quedaba muchas veces subordinado a este tipo de relaciones personales entre los directores, generalmente pertenecientes a círculos de élite. Debe destacarse además que Ruiz Moreno estaba muy al tanto de las cuestiones indígenas en los Territorios, de modo tal que constituía un interlocutor de gran utilidad para los objetivos del Museo.

El segundo punto nos conduce de forma directa al planteo del artículo y se vincula a la especificidad de los "pedidos" y en particular a la inclusión de restos humanos en los mismos. Si bien el expediente que se conserva en el Museo Etnográfico ${ }^{13}$ no incluye el listado de objetos, la existencia de la solicitud de esqueletos se desprende textualmente de algunas respuestas. Por ejemplo, el comisario de Apóstoles explicaba: "no pude aún dar con ninguno de los objetos del detalle, y se ignora en este Departamento que haya existencia en él de cráneos ó esqueletos indígenas." ${ }^{14}$ Por su parte, el comisario de Santa Ana, orientado hacia los esqueletos de "antaño" indicaba que "los antiguos moradores de este Departamento ignoran dónde los jesuitas tenían instalado el cementerio". ${ }^{15}$

Es importante destacar que la imposibilidad de encontrar objetos y cuerpos era explicada por la inexistencia de indígenas en tierra misionera. El comisario de Corpus sostenía:

[S]i bien en épocas anteriores han aparecido en Tabay grupos de tres o cuatro indios Cainguá, hoy con motivo de la paralización de los trabajos en los obrajes se han retirado hacia el norte del Territorio, no conociendo lugar en donde hayan sepultado algún cuerpo de aquellos ni la existencia de los objetos que usaban los mismos pues, en la actualidad, todos poseen armas i útiles modernos. Según datos obtenidos de algunos viajeros, frente a Paraguay existen dos colonias de indios Guayaná y Cainguá. ${ }^{16}$

18 Es en la respuesta de un "especialista" consultado al respecto, Francisco Fouilliand, que aparecen explicitados ordenadamente los elementos pedidos por Ambrosetti: armas, instrumentos de agricultura, de música, de alfarería, adornos, tejidos, objetos antiguos urnas, vasos, ollas, hachas, de piedra, bolas, anzuelos, tembetás, etc., cráneos y esqueletos. Sobre este último punto, Fouilliand se explayaba en precisiones técnicas acerca de la improbabilidad de encontrar cuerpos conservados:

Pedidos del Museo Etnográfico. Cráneos y esqueletos. Solamente adquiriendo algunos indios recién muertos en el Paraguay podrían conseguirse cráneos y esqueletos, pues la falta de cloruro de sodio en las tierras de Misiones hace que los huesos no puedan conservarse enterrados sino durante unos pocos años y más particularmente los de indios que no condimentan sus comidas con sal.

Además, en Misiones no quedan indígenas, salvo un pequeño grupo de indios mestizos que se titulan Guayanás que merodean en las cercanas de San Pedro y cuyo 
cacique, un tal Maidana, era un blanco nacido en Santo Tomé. Otro grupo insignificante merodea entre el arroyo Once Vueltas y Campo Grande; probablemente en las ruinas de Mbororé, que aun no han podido hallarse. ${ }^{17}$

No queda sino la posibilidad de comprar algún difunto Guayaquí en costa Paraguaya, donde abundan dichos indios, para mandar su osamenta al Museo. El Guayaquí es el Guaraní absolutamente primitivo, pues pertenece a la edad de piedra, no conoce el arte del fuego ni construye choza (el resaltado nos pertenece). ${ }^{18}$

La cita, por demás elocuente, permite comprender cómo la adquisición de cráneos y esqueletos de personas recientemente muertas no parecía implicar dilema ético alguno. Esto permite preguntarse si la compra de recién fallecidos por instituciones científicas pudo haber constituido una práctica más común de lo que se suele pensar. Otro punto que debe destacarse es que esta correspondencia formaba parte de un expediente institucional, lo que implica el conocimiento, involucramiento y aval de la Dirección de Territorios Nacionales en la búsqueda. En otras palabras, una directa cooperación del Estado.

Fuera de este expediente, el rastreo de otras respuestas epistolares particulares indica que Ambrosetti desplegó el pedido de elementos y restos humanos a todo tipo de contactos. El 3 de junio de 1913, le escribía al Dr. Jorge Larrosa - de viaje con su novia por el sur- adjuntándole una lista de objetos e indicando que todo lo que consiguiera le sería útil, incluso duplicados para canjes, agregando explícitamente: "si me puede pescar en el viaje algún cráneo también será espléndidamente recibido". ${ }^{19} \mathrm{El} 6$ de agosto de 1914, dos meses antes de su muerte, el expresidente Julio Argentino Roca (1880-1886) le escribía:

En respuesta á su atenta de fecha 29 del corriente, me es grato manifestarle que he reiterado las órdenes para que sean recogidos los objetos y esqueletos indígenas que puedan encontrarse en mis establecimientos.

Con mucho gusto remitiré cualquier hallazgo al Museo Etnográfico, contribuyendo así a la obra que con tanta inteligencia y celo Ud. realiza.

21 A partir de estos ejemplos, es importante establecer algunas consideraciones iniciales. La producción de trabajos que han abordado el problema de los restos humanos de indígenas en museos $-\mathrm{y}$ consecuentemente, el de las políticas de restitución (Arenas y Pinedo 2005; Badenes 2006; Colectivo Guías 2008; Curtoni y Chaparro 2011; Tamagno 2009; Verdesio 2011; entre otros) - se han referido generalmente al Museo de La Plata, donde ha sido posible identificar gran cantidad de casos. Ahora bien, un examen del problema en relación al Museo Etnográfico permite contrastar y analizar con mayores datos si este tipo de prácticas eran excepcionales, si deben ser vinculadas a individuos determinados o si, por el contrario, eran parte de un quehacer institucional corriente y compartido en la época, no por ello menos cuestionable.

Para esto, deben considerarse en primer lugar las diferencias de desarrollo de las "subdisciplinas" en cada caso. Mientras que el Museo de La Plata fundó tempranamente la Sección de Antropología, esta no fue tan importante en el inicio del Etnográfico, posiblemente en sintonía con la tendencia personal de Ambrosetti, más orientada hacia las prácticas socioculturales, arqueológicas y folklóricas. De este modo, el desarrollo de esta Sección ${ }^{20}$ fue relativamente más lento que las otras y, en consecuencia, el número de publicaciones de esta especialidad fue prácticamente inexistente en ese periodo. ${ }^{21}$ No obstante, tratándose de un espacio de formación, la antropología debía integrarse y los cursos impartidos supusieron la necesidad de contar con restos óseos, a veces adquiridos específicamente a esos fines, ${ }^{22}$ tal como ilustra el pedido elevado al decano, para que 
solicite a la Facultad de Ciencias Médicas el siguiente material, "indispensable para estudios comparativos de antropología": Territorios Nacionales también pudo haber sido impulsada por la necesidad de conformar la Sección Antropológica, la cual no llegó a terminarse antes de la temprana muerte de Ambrosetti. Si así hubiera sido, es posible imaginar la gran utilidad que significaría la avanzada militar sobre el Gran Chaco para esos fines, sobre todo si se tiene en cuenta que las ya poco cuestionadas prácticas científicas sobre cuerpos indígenas, menos aún lo serían en un contexto de conquista territorial. Si a esto se le suma la escasez de materiales etnográficos de esa región en las vitrinas del Museo, las campañas militares proveerían entonces una vía valiosa de adquisición, que sería aprovechada por Ambrosetti.

\section{Campañas militares y expansión del Estado-nación sobre el Gran Chaco} cabo, debemos recuperar brevemente el contexto de la avanzada militar del Estadonación en este territorio, desarrollada desde fines del siglo XIX hasta entrado el siglo XX. A diferencia de lo que sucediera en otras regiones del país, aquí al control territorial se sumó la necesidad de disciplinar a las poblaciones originarias para convertirlas en mano de obra, a raíz de la demanda de diferentes sectores vinculados a la agroindustria.

El proceso de expansión sobre el Gran Chaco se inició en 1870 y se sostuvo hasta la década de 1930, a través de la intervención directa y sistemática sobre el territorio por medio de campañas militares que desarrollaron diversas estrategias, con el objetivo de ampliar la soberanía territorial del Estado y someter a las poblaciones preexistentes. La mayoría de las expediciones militares realizadas a fines del 1800 contaron con la colaboración de las

Corpus, Vol 6, No 1 | 2016 
sociedades científicas de la época y con la participación de geógrafos, naturalistas y botánicos (Arenas 1989) entre otros especialistas dedicados a estudiar las riquezas y recursos naturales de los territorios y su potencial explotación. De esta manera, el campo político-militar y el científico se beneficiaron mutuamente, poniendo en evidencia una relación que perduraría por muchos años.

A continuación mencionaremos brevemente tres de estas campañas. La primera, encabezada por el general Benjamín Victorica en 1884, durante la primera presidencia de Julio Argentino Roca, es considerada como una de las más importantes debido a la sistematicidad y violencia con la que se desarrolló, en comparación con las campañas anteriores. El despliegue de las fuerzas armadas incluyó regimientos de infantería, caballería, línea y marina, que con el objetivo principal de consolidar la ocupación territorial y marcar los límites de la soberanía del Estado-nación, logró además someter a parte de las poblaciones indígenas chaqueñas.

Aunque esta campaña sería considerada exitosa, en tanto desde el discurso oficial se afirmaba haber logrado el dominio efectivo sobre el territorio y sus habitantes, aún persistían zonas que se encontraban por fuera del control estatal. En este sentido, las campañas siguientes tuvieron como propósito consolidar ese dominio de forma definitiva y someter a los indígenas que aún se resistían. Durante el desarrollo de las mismas, los grupos que lograron sobrevivir fueron despojados de su territorio y privados del acceso a montes y ríos, los cuales garantizaban sus tradicionales formas de subsistencia. Las tierras conquistadas por el Estado fueron posteriormente redistribuidas, formándose así grandes propiedades dedicadas principalmente a la ganadería, la producción de azúcar y la explotación forestal (Iñigo Carrera 1984, Gordillo 1995, Trinchero 2000, Brunatti et al. 2002). De este modo, fue gestándose progresivamente la necesidad de los indígenas de buscar nuevos medios de subsistencia, que determinó que se vieran obligados a vender su fuerza de trabajo, principalmente a los obrajes e ingenios azucareros.

La campaña del general Teófilo O'Donnell, decretada por orden del entonces presidente Figueroa Alcorta en julio de 1907, continuó el avance de la llamada línea de fortines con el propósito de ocupar totalmente el territorio y promover su ocupación por la población no indígena. Entre sus objetivos se pretendía construir caminos que facilitaran el transporte, aprovisionamiento y el comercio, así como establecer líneas telegráficas que permitieran una mejor comunicación, principalmente entre los sitios ocupados y los nuevos poblados que se iban estableciendo a medida que avanzaban las campañas. Para ello se continuó atacando violentamente a las poblaciones originarias que resistían el avance militar. Los caciques que se rebelaron fueron asesinados o capturados como prisioneros de guerra hasta decidir su destino, siendo en muchos casos trasladados a espacios concentracionarios; en otros, obligados a incorporarse como trabajadores en establecimientos productivos, o como miembros de las tropas de frontera, etc.

La campaña del coronel Enrique Rostagno en 1911 siguió inmediatamente a la anterior. Nombrada desde el comienzo como "Fuerza de operaciones en el Chaco", fue considerada como el último gran avance sobre la región. Con ella el centro-oeste de las actuales provincias de Formosa y Chaco fue incorporado definitivamente y se logró la "pacificación final" de las poblaciones indígenas que aún no habían sido sometidas.

Si bien con esta campaña se concluyeron los objetivos determinados en 1884 (Iñigo Carrera 1984) y el dominio sobre los indígenas parecía ser un hecho, esto no fue suficiente. Era también necesario hacer efectivo el disciplinamiento y la conversión de éstos en "trabajadores útiles". En este marco, en el informe dirigido al Ministro de Guerra 
Gregorio Vélez, Rostagno menciona la necesidad de enseñarles a los indígenas a trabajar la tierra y que para ello se designara un lugar dónde podrían relocalizarse las "tribus" sometidas "espontáneamente" (Rostagno 1969 [1911]). Rostagno refería como parte de los argumentos la situación vulnerable de los indígenas, que motivaba supuestos pedidos de algunos caciques:

[A]demás de los 1600 indios de los caciques Coyahiqui, Sobiacay, Solinkí, Ilirí Santiaguito y Natochí de la tribu de Caballero que se someten para aprender a sembrar; de los 1000 mocovíes de Pedro José que ya no piden sólo tierras, sino hasta escuelas, están el mismo cacique Caballero y el cacique Jara con 2000 individuos pidiendo al C9 [Caballería 9] que los haga trabajar donde quiera, poniendo como condición que el regimiento sirva como contratista, tan grande es la desconfianza que tienen de ser robados. Puedo agregar también que los más de 1500 Pilagaes [pilagás] que obedecen al cacique Nella-Lagadik en las lagunas de Killolkai (cabeza de tigre) y Pedagananaes del Pilcomayo central, que recorren gran parte del Pilcomayo superior, me han manifestado sus deseo de que se les dé trabajo de un modo permanente (el resaltado nos pertenece). ${ }^{24}$

La propuesta de Rostagno fue escuchada y en consecuencia el 27 de octubre de 1911 se promulgó el decreto del Gobierno Nacional que establecía la creación de la Reducción de Indios de Napalpí. Convertida en el prototipo de reducción forestal-agrícola que se esperaba adoptar en los futuros establecimientos de la región, se nombró como su primer director al reconocido naturalista Enrique Lynch Arribálzaga. ${ }^{25}$

En las zonas en las cuales se había logrado someter a las poblaciones originarias se optó por una retirada del Ejército; aquí las reducciones completarían la "tarea civilizatoria". De esta manera, la coerción física se fue complementando con nuevas formas de control social, generadoras de cuerpos dóciles (González Stephan 1999, Foucault 2001) impulsadas ahora desde el Estado, en íntima vinculación con las necesidades del mercado. Esta modalidad se articuló con las tres misiones franciscanas previas a Napalpí - San Francisco de Laishí (1900), Nueva Pompeya (1900), San Francisco Solano de Tacaaglé (1901) - y prosiguió con otras tres reducciones fundadas posteriormente -Bartolomé de Las Casas (1914), Francisco Javier Muñiz (1935) y Florentino Ameghino (1935)-. ${ }^{26}$ De este modo, en menos de 40 años se consolidó un sistema de control de la fuerza de trabajo indígena en los entonces Territorios Nacionales de Chaco y Formosa.

En cuanto a la antropología, las misiones, reducciones así como los ingenios y obrajes se convirtieron en lugares preferenciales, tanto para quienes estaban interesados en realizar estudios sobre individuos vivos ${ }^{27}$ como para aquellos que querían aumentar las colecciones de sus instituciones a través de la adquisición de diferentes tipos de bienes.

\section{El Museo Etnográfico y las campañas militares}

Pegoraro (2005) indica que el primer acercamiento del Museo Etnográfico a la región chaqueña se realizó a través de la expedición de Salvador Debenedetti a Chaco y Jujuy en 1909, quien trajo consigo 348 objetos ceremoniales y domésticos de los grupos indígenas de la zona. Previamente, sin embargo, Ambrosetti había planteado al decano de la Facultad la importancia de convocar al Ejército que emprendía la campaña hacia esa región, con el expreso fin de que colaborara con el Museo. Ambrosetti confiaba en que la ilustración de O'Donell le permitiría darse cuenta de la importancia que el asunto merecía: 
En vísperas de iniciarse la campaña de avance de fronteras en el territorio del Chaco por las tropas nacionales, creo que sería muy oportuno solicitar del Gefe de dichas fuerzas, General D. Carlos O'Donell, que se sirviera ordenar a los Gefes encargados de las operaciones de vanguardia la reunión y envío de objetos etnográficos con destino al Museo de esta Facultad. Las tribus del Chaco tienden á alejarse cada vez más ó á desaparecer debido al contacto del hombre blanco; y por esto es que es urgente reunir el mayor material posible, con el cual se puedan estudiar sus usos y costumbres, y hacer las comparaciones etnográficas necesarias (el resaltado es nuestro). ${ }^{28}$

A partir de allí, el Museo recibió contribuciones de miembros del Ejército. Entre ellos, los más importantes fueron el mayor Pedro Cenóz - del Regimiento $9^{\circ}$ de Caballería de Línea - y el teniente coronel Francisco Magín Guerrero - del Regimiento $7^{\circ}-$, quienes enviaron colecciones etnográficas y antropológicas de los indígenas del Chaco. ${ }^{29}$

Hay que destacar aquí que si bien en la carta que Ambrosetti le envió al decano para el Ejército, el detallado listado de objetos requeridos no incluía restos humanos, ${ }^{30}$ en correspondencia de octubre de1909 Cenóz le comunicaba en forma directa al director del Museo que le había enviado una encomienda dirigida al decano de la Facultad, conteniendo objetos de indios. No obstante, le aclaraba que:

Lo principal de su encargue que son los esqueletos de indios, lamento el tener que anunciarle que a pesar de mi empeño personalmente llevado a cabo, no he podido conseguir casi aún con ofrecimientos de todo género, pues hasta los mismos padres misioneros quienes son los que pudieran tener mayores facilidades por cuanto hace mayor tiempo que actúan entre los indios, no me han podido conseguir indicarme donde pudiera existir algún enterratorio (el resaltado nos pertenece). ${ }^{31}$

En este sentido, llama la atención que el pedido de restos óseos no aparezca incluido en el listado adjunto a la carta del decano. La inexistencia del original nos impide confirmar cualquier hipótesis, pudiendo el pedido haberse incluido en hoja aparte o haberse preferido - por razones que hasta ahora desconocemos- movilizarse por medio de una correspondencia más personalizada. En cuanto a los más de 20 objetos etnográficos enviados por Cenóz en esa oportunidad, Ambrosetti se mostró agradecido, señalándole unos días después al decano que:

Este hecho además del valor de los objetos, tiene importancia pues es el primer paso que se da respecto de la cooperación de los señores Gefes del Ejército Nacional en el fomento del Museo de esta Facultad y es por esto que pido al Sr. Decano quiera agradecer al Sr. Mayor Cenóz este envío como merece y en forma que estimule esa cooperación que tanto necesitamos (el resaltado nos pertenece). ${ }^{32}$

Para Pegoraro (2009, p. 209):

[L]a idea de utilizar al Ejército y las gobernaciones a través de jerarquías institucionalizadas, constituía un modo de facilitar la transmisión de las instrucciones, ya que estas se derivaban por medio de círculos oficiales y cumplían con las instancias administrativas de cada organismo estatal.

Ciertamente, la "eficaz participación de miembros de nuestro Ejército nacional" era valorada por Ambrosetti, tal como enunciara respecto de Cenóz, o al recibir las primeras dos donaciones de Guerrero, un cráneo y un juego de flechas tobas. ${ }^{33}$ Por su parte, los miembros del Ejército también parecían contentarse con la posibilidad de cooperar en este tipo misión científica y prestar "un buen servicio al país y a la ciencia", tal como manifestaba el propio Cenóz. ${ }^{34}$

Ahora bien, más allá del pragmatismo orientado al objetivo de formar colecciones, nos interesa profundizar en las implicancias de este vínculo, en tanto el mismo constituyó 
una alianza concreta entre una institución científica dedicada al estudio de la población indígena -el Museo Etnográfico- y las fuerzas represivas militares que en ese mismo momento se ocupaban de su exterminio o de su sometimiento para fines de explotación. En otras palabras, el "alejamiento" y la "desaparición" del indígena señalados por Ambrosetti eran el resultado de la misma acción del Ejército al que se le encargaba el "rescate" de sus objetos y eventualmente, de sus propios cuerpos. Desde esta perspectiva, revisaremos tres formas concretas de la práctica de recolección de objetos y restos humanos de indígenas chaqueños para el Museo Etnográfico, en contextos específicos de violencia: la prisión, las reducciones y la muerte en enfrentamientos.

\section{La prisión}

Como ya hemos mencionado, la carta de Ambrosetti elevada al decano con destino a $\mathrm{O}$ 'Donell adjuntaba un abarcativo y detallado listado de objetos etnográficos a remitir al Museo, en el cual se aclaraba:

No importa que vengan muchos duplicados, en los objetos etnográficos suele haber diferencias muy interesantes.

Los objetos deberán venir acompañados si es posible, del nombre indio que tengan y esto será fácil obtenerlo de los prisioneros [y/o] de los indios mansos. Indispensable será que traigan todos el nombre de la tribu o nación a que pertenecen (el resaltado nos pertenece). ${ }^{35}$

La cita indica cómo el contexto de prisión de los indios era percibido como una situación beneficiosa para el acopio de objetos de interés científico y datos útiles para su exacta catalogación. Aún sin poder saber si estas indicaciones fueron efectivamente concretadas, su sola enunciación permite señalar la absoluta falta de empatía hacia los sujetos que Ambrosetti pretendía estudiar, quienes solo eran valiosos como productores de objetos y facilitadores de información. La ciencia, así, sumaba su propia violencia al contexto de sometimiento, quitándoles a los indígenas -tanto a los "mansos" como a los belicosos apresados- sus pertenencias y saberes, convirtiéndolos de este modo en "colaboradores" obligados del Museo.

\section{Reducciones y misiones}

51 Como espacios de disciplinamiento, las misiones y reducciones jugaron un rol central en la sedentarización de los indígenas y su conversión en trabajadores estacionales. Suele referirse a las mismas como abastecedoras de mano de obra barata; sin embargo, menor es su examen como "centros" de relevamiento de datos e investigación científica. En este sentido, continuando con la línea de "aprovechamiento" de las situaciones de confinamiento, el traslado de los antropólogos a ingenios o reducciones facilitaban el contacto con los sujetos allí concentrados, sin la necesidad de exponerse a los peligros y adversidades del terreno. Este fue el contexto específico de la ya mencionada expedición de Debenedetti en 1909, única "misión etnográfica" llevada a cabo por el Museo durante la dirección de Ambrosetti (Pegoraro 2009, p. 22). Por otro lado, estos espacios también se consideraban privilegiados a los fines de provisión de objetos para las colecciones.

En este sentido, los directores de reducciones y misiones no solo podían facilitar el acceso al campo sino que también podían ser útiles como "recolectores". Para ello, Ambrosetti aprovechó el vínculo personal ${ }^{36}$ que mantenía con Lynch Arribálzaga, por entonces director de la Reducción de Napalpí, a quien le escribió una carta con una especial 
solicitud. La poca consideración demostrada por Ambrosetti hacia la situación de los indígenas prisioneros resulta aún menor si se compara con el pedido a su amigo de objetos etnográficos y esqueletos indígenas. Lynch, quien habitualmente colaboraba con diferentes instituciones enviando objetos naturales y etnográficos ${ }^{37}$, le respondía:

No he podido menos de reír ante su apresuramiento por pedirme cráneos y esqueletos de mis protegidos, cuya vida y bienestar son precisamente mi mayor preocupación. Además, si yo me ocupara de desenterrar indios, ¿no cree ud. que disminuiría mi poco prestigio entre ellos?

Pero, tranquilícese Ud.; algo puedo hacer por ese gran Museo Etnográfico, que tanto deseo conocer y a cuyos progresos me agradará mucho contribuir. En efecto, hay por estas cercanías varios enterratorios indígenas ya viejos, sobre los cuales es posible obtener algunos datos; unos son tobas y otros vilelas. Contando con algunos fondos y valiéndome de personas de mi confianza, [para que reserven] mi intervención en el asunto, puedo hacerles buscar, para retirar de ellos los cuerpos adultos y cualquier objeto que lo acompañe.

Por otro lado, esto sí en la Reducción de Napalpí y en otros puntos donde tenga yo que hacer con los indios, compraré por su cuenta armas, tejidos y utensilios de su uso (el resaltado es nuestro). ${ }^{38}$

53 Marcando un límite ético respecto de sus “protegidos”, Lynch sólo aceptó la misión de conseguir objetos etnográficos, delegando el encargo de los huesos en otras personas. Lo expresado en su carta pareciera evidenciar que la exhumación de restos humanos y su envío a instituciones científicas resultaba problemática para quienes dirigían instituciones destinadas al resguardo de los indígenas. No obstante, tal como se observa en la siguiente cita, Lynch no invalidaba la acción en sí misma, sino que esta fuera practicada en la reducción a su cargo. En consecuencia, proponía otras alternativas:

Según el administrador de la Reducción, gran amigo y conocedor de los indios del Chaco, no hay inconveniente en extraer esqueletos de individuos a quienes no conocieron, tal que enemigos suyos; de modo que me ha prometido buscarlos y sacar todo lo que pueda. Precisamente da cuenta que en aquellos campos, hubo grandes combates, con las huestes del famoso "cacique inglés" 39 , y los tobas, aseguran que el nombre que le dan al lugar, significa "los muertos", aludiendo a los muchos que quedaron (el resaltado es nuestro) ${ }^{40}$

54 Cabe destacar además que la referencia al cacique Inglés permite ubicar a estos muertos en combates entre mitad de la década de 1870 y 1884, año en que dicho cacique fue asesinado. Es decir, tan sólo 28 años antes de la carta. Por otro lado, a partir de la solicitud de restos mortales realizada por Ambrosetti, Lynch Arribálzaga se puso en contacto con González Leiva, guardabosques de la región "que capitanea Eduardito" - cuñado de Ambrosetti e hijo de Eduardo Holmberg-. En correspondencia del 7 de mayo de 1913, Lynch le comunicaba a Ambrosetti las novedades que le transmitiera González Leiva:

[E]n el campo de la matanza que el $7^{\circ}$ de caballería del otro lado del Bermejo, han sido [encontrados] esqueletos de indios así como objetos domésticos abandonados. Me dijo, además, que si Eduardito le envía una orden de hacer una gira por esos lugares y se le dieran elementos de transporte, él irá a coleccionarlos para el Museo. Aproveche Ud., pues, cuanto antes la ocasión de obtener lo que desea en abundancia (el resaltado es nuestro). ${ }^{41}$

Mientras tanto, el 20 del mismo mes, el propio Eduardito le escribió a Ambrosetti una afable carta en la que le informaba la donación de su esposav-Libia de Holmberg- de un cráneo de Rigoleto, hallado en el centro del Chaco. ${ }^{42}$ Respecto de la propuesta que hiciera González Leiva, recién un año después Lynch le comunicaría a Ambrosetti lo que había ocurrido: 
[E]n Noviembre ppdo, fue [González Leiva] en busca de los esqueletos del campo de combate con el $7^{\circ}$ de caballería para que se encontrara con que las fieras los habían destrozado y lleváronse algunos huesos, lo que es más grave. ya carecían de cráneos, porque los indios acostumbran, según él, enterrar los de los guerreros muertos en la pelea. Pero recientemente he sabido donde está sepultado, desde hace ocho meses, un indio que murió mordido por una víbora y agrega que conoce también el sitio en que está enterrado el famoso cacique llamado Viejo o Ñato, desde hace 7 años. Está dispuesto a ir en busca de estos esqueletos si le procuramos una autorización del jefe militar respectivo para extraerlos y la cantidad de $\$ 150$ para movilidad y gastos de excursión. "Una voy en compañía, me dice el Sr. González Leiva, no he de volver sin dos, por lo menos" (el resaltado es nuestro). ${ }^{43}$

Aunque no tenemos certezas respecto de la concreción de esta excursión a partir de los documentos de colecciones y de la Memoria de 1914-1915 podemos considerar que por lo menos algunos de los restos humanos que ingresaron al Museo enviados por González Leiva podrían corresponderse con los mencionados en esta carta. Respecto del cacique Ñato no hay ningún dato que confirme su ingreso, por lo menos con esa identificación.

Es importante destacar que los agentes involucrados y/o autorizados para la tarea de apropiación de los restos mortales indígenas mencionados en las fuentes guardabosques, encargados, administradores, militares- eran funcionarios públicos que operaban amparados por el Estado, partícipe indiscutible y directo de tales prácticas. Por otro lado, las menciones a los "muertos en combate" constituyen una evidencia contundente que confirma la búsqueda de restos humanos indígenas en los mismos espacios donde habían sido muertos por los regimientos militares, con el fin específico de ser dirigidos al Museo.

\section{Caciques-trofeo}

Lo dicho hasta aquí echa luz sobre las formas que tomó la acción de recolección de objetos y restos humanos con destino al Museo Etnográfico. Repasaremos a continuación, a partir de la escasa información disponible, los ingresos efectivos de restos humanos entre las remesas enviadas desde el Chaco en la época analizada, algunas de las cuales fueron realizadas directamente por militares ${ }^{44}$ Según la tabla elaborada a partir del cruzamiento de distintas fuentes, podemos determinar el ingreso, entre los años 1904 y 1916, de por lo menos quince cráneos y dieciséis esqueletos completos. La ausencia de una clasificación estandarizada y la variedad de formas en las cuales se han registrado esos ingresos produce informaciones dispares. En algunos pocos casos se catalogan los restos solo como "humanos"; en la mayoría se refiere a "indios"; en algunas ocasiones se menciona el pueblo -toba, pilagá, mocoví, "chiriguano"-; solo dos veces se detalla el género femenino y solo en el caso de los caciques se los identifica: cráneo del cacique Carayá y esqueleto del cacique Illirí y de su hijo. ${ }^{45}$

59 A diferencia de la mayoría de los cuerpos, anónimos y consignados solo con sus datos de procedencia $-\mathrm{y}$ del donante, vendedor o corresponsal-, los nombres de estos caciques constituyen el único dato que permite, para estos casos, establecer algún acercamiento a la historia de las personas. No obstante, dado que la información que hemos hallado sobre ellos hasta el momento es escasa y la dificultad metodológica de reunir datos fragmentarios requiere un trabajo mucho más extenso, debemos aclarar que el presente artículo constituye solo un primer paso en esta búsqueda. En este sentido, nos proponemos seguir avanzando en el rastreo de las trayectorias de las víctimas de estas 
prácticas, la identificación de sus grupos de origen y las posibles vinculaciones con actuales descendientes, con el objetivo de recuperar aspectos personales de quienes han quedado desidentificados y objetualizados en el contexto de las colecciones científicas.

Con respecto al cráneo del cacique Carayá, los datos acerca de su ingreso al Museo Etnográfico son casi inexistentes. Aparece mencionado en la Memoria impresa de 1904-1912 como una donación del Museo de Bellas Artes. En el Legajo de Colecciones correspondiente no aparece ninguna mención al mismo. Es más, en la lista de objetos donados no se registran restos humanos de ninguna procedencia.

61 Minnitti Morgan (2011, p. 27) refiere a Carayá como lenguaraz, baqueano y colaborador del Ejército que en la década de 1880 fue llevado a Buenos Aires, junto con el cacique Pichón, donde recibió del Gobierno Nacional "un salvoconducto para que ninguna autoridad del Chaco los moleste" y “\$100.- en monedas de plata". Aparentemente, luego de esta visita a la capital regresó al norte. También se menciona que estuvo involucrado en el episodio de la emboscada y asesinato del importante cacique Cambá, que según la descripción del coronel Fotheringam era "un indio gigantesco, muy moreno, de forma atlética y tenía mucho prestigio entre los tobas" (1908, citado en Ruiz Moreno 2012, s/p). Cambá había desafiado a las tropas y su captura había sido encargada al capitán Rosendo Fraga, quien contaba con el cacique Carayá y seis indios como "indios auxiliares". En los primeros días de diciembre de 1884, Fraga, prevenido por Carayá de estar siendo observados, dio finalmente con Cambá y sus 200 indios. El cacique recibió un tiro y quedó tendido y en ese momento "Carayá identificó al jefe enemigo caído, y antes que pudiese ser recuperado por los suyos, un cabo Luna avanzó hacia él corriendo, lo ultimó a puñaladas, le cortó la cabeza y la clavó en la punta de su propia lanza" (Ruiz Moreno 2012, $\mathrm{s} / \mathrm{p})$.

No hemos podido recabar mayor información sobre Carayá, ni sobre cómo llegó su cráneo al Museo Nacional de Bellas Artes, desde donde fue donado al Etnográfico. Nos preguntamos sin embargo, si este envío habrá sido realizado por los militares cercanos al cacique $\mathrm{y}$, en este sentido, creemos posible considerar que la distinción entre indio "auxiliar" (amigo) o enemigo era indiferente al momento de enviar sus restos a los respectivos museos, siendo todos ellos considerados como bienes de "interés científico".

Con respecto al cacique Illirí, sabemos que su esqueleto completo y el de su hijo ingresaron al Museo Etnográfico enviados por el teniente Francisco M. Guerrero. La correspondencia entre este y Ambrosetti - conservada en el AFDME- permite comprender que el teniente, quien envió varios restos humanos de indígenas de la región chaqueña (Ver Tabla) se encontraba bien dispuesto a colaborar con la adquisición de objetos etnográficos, esqueletos y cráneos en beneficio del Museo, en tanto se sentía "orgulloso como argentino porque nuestro museo etnográfico prospera rápidamente". Respecto del envío de los restos de Illirí, en carta del 2 de octubre de 1913 le confiaba a Ambrosetti:

Cumpliendo lo prometido cuando estuve en esa le mando para ese Museo por la agencia Mihanovich dos cajones conteniendo los restos del cacique Ilirí y su hijo que fueron muertos el 4 de noviembre 1912 en una sorpresa. Este cacique fue el de más nombradía de la tribu Collagá que va en camino de extinguirse. ${ }^{46}$

64 Aunque la información sobre la vida y la muerte de Illirí es fragmentaria y confusa, el uso del término "sorpresa" nos permite inferir que la última puede haber sido producto de una emboscada tendida por el Ejército. Para completar estos datos, hemos triangulado 
distintas fuentes, que nos permiten recuperar parte de su biografía, aunque algunos puntos siguen siendo contradictorios.

Beck (1994, p. 60) señala que el propio O'Donnell se entrevistó en octubre de 1907 con los caciques Illirí y Matolí, durante una recorrida de 300 leguas por el territorio de Formosa y Chaco, "a quienes convenció para que aceptaran el proyecto de colonización". En 1909 se produjo una rebelión encabezada por Matolí, la cual implicó una serie de ataques a los fortines de Brown, Warnes, Wilde, Urquiza y Arenales (Beck, 1994; Tamagno et al. 2015). Algunas de las reuniones de O'Donnell con grupos indígenas fueron fotografiadas por el mayor Pedro Cenóz (Ver imagen 1).

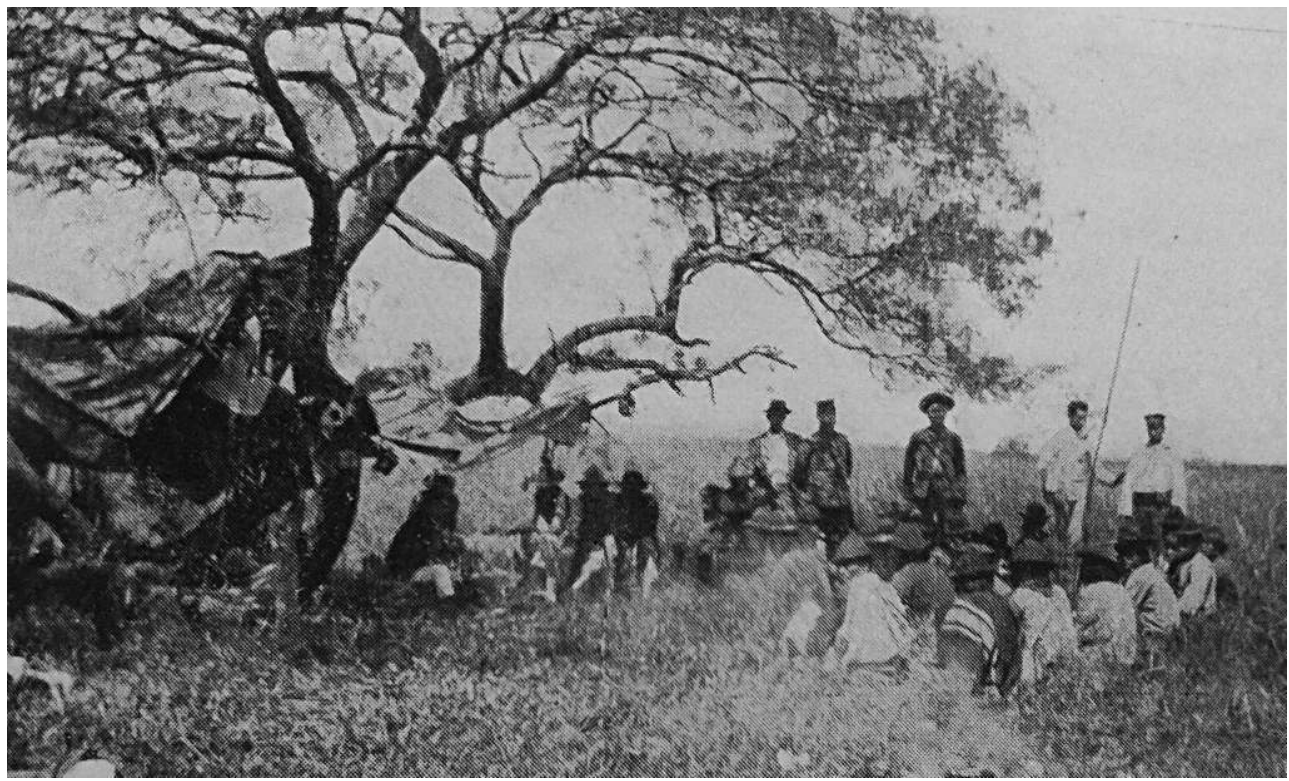

Imagen 1. Las tropas a cargo del general O’Donnell. Fuente: Cénoz (1913).

Por otro lado, una Memoria escrita por un ex soldado confirma la muerte de Illirí. Se trata Agustín Santiago ${ }^{47}$ miembro del Regimiento $9^{\circ}$ de Caballería de Formosa -creado años antes por O'Donnell- "en pie de guerra, bajo severos códigos disciplinarios, internados en las vírgenes selvas, donde la hostil presencia del indio salvaje debería ser sometida por las Fuerzas Armadas con fines civilizadores" (De Marco 2003, p. 212). En un contexto de escasas condiciones y muchos peligros, un punto fundamental consistía en:

[A]tender y consolidar indicaciones del oficial instructor sobre la mentalidad del aborigen -más por su constante cobardía, asechanza, oculto en la selva, al paso de las comisiones que circulaban ininterrumpidamente entre fortines- que por su bravura. Tribus de diferentes razas: tobas, pilagás, guaraníes, lenguas, chunupies, y otras. ${ }^{48}$

Entre los datos generales que la fuente aporta, el ya anciano conscripto Santiago eligió como único "acontecimiento destacable" para relatar, el que tituló como:

Captura de un cacique "vivo o muerto": por disposición del Ministerio de Guerra, debimos buscar al cacique conocido por el nombre de Iliri, de raza toba, que con su numerosa tribu sorprendió y mató al capitán Solari cuando cruzaba una picada con seis soldados. La picada es una perforación que los soldados, utilizando machetes y hachas, abren entre los árboles para que puedan circular mulas de transporte de víveres y comisiones oficiales de servicio, y que solo lo pueden hacer una detrás de otra. Para los indígenas es de gran utilidad, favoreciéndoles atacar sorpresivamente con flechas, ocultos entre la maleza y a muy corta distancia. 
La consigna de prenderlo vivo o muerto se logró por el $2^{\circ}$ Escuadrón, al que yo pertenecía, que después de tres días de camino fue alcanzado por una tribu. Producido el combate, los indios con flechas por no disponer de armas de fuego, lo que los ubicaba desfavorablemente para la acción, que fue muy breve, el cacique, entre otros, resultó muerto. Lo más penoso fue transportar el cadáver envuelto en bolsas, a lomo de mula, hasta la Gran Guardia, que así era la orden. Se llegó después de dos días de camino, con el cuerpo del indio putrefacto. De inmediato se procedió a descarnarlo, hirviéndolo, extrayéndole con cuchillo la carne adherida, hasta que los huesos, ya limpios, se introdujeron en latas de keroseno con cal, para remitirlos a Buenos Aires. Posiblemente estén en algún museo. En el Chaco santafesino hay un pueblo con el nombre de capitán Solari (el resaltado nos pertenece)..$^{49}$

Los datos que aporta la fuente son coincidentes y complementarios con otros relatos que se centran en destacar la heroica muerte del capitán Solari en la denominada "Sorpresa del Estero" de $1^{\circ}$ de junio de 1912. En estos casos, solo se refiere genéricamente al "grupo de indígenas" que supuestamente emboscara y matara al capitán. Por ejemplo, López Piacentini (1976) relata que Solari habría llegado a fines de 1911 a Presidencia Roca desde Resistencia, como Jefe del Tercer Escuadrón del Regimiento $7^{\circ}$ de Caballería (de 500 efectivos) y allí recibió instrucciones para dirigirse al campamento del $9^{\circ}$, con asiento en Formosa. En 1912 este Regimiento avanzaría $173 \mathrm{~km}$ desde Formosa, cumpliendo la orden de Rostagno de dar seguridad a la construcción del Ferrocarril Embarcación-Formosa y del decreto presidencial de 8 de febrero de 1912 de "poblar" el territorio. Ese decreto indica que el jefe del Regimiento $9^{\circ}$ era justamente el coronel Francisco M. Guerrero, fundador del pueblo Comandante Fontana y, según los documentos del Museo Etnográfico, el donante del esqueleto de Illiri (Ver Tabla 1).

Solari fue enviado a fines de mayo de 1912 a patrullar la línea de fortines del Bermejo partiendo del Fortín Lapachito en Colonia Elisa, con el sargento Domingo Arce y un grupo de entre quince y veinte hombres recién incorporados. La primera versión sobre lo acontecido, presentada por López Piacentini, sostiene que apenas iniciado el traslado hacia Formosa se produjo el encuentro con los indígenas:

Tras breve marchar (...) los soldados del 3ํㅡㄹ Escuadrón del 7ํ divisaron una toldería emplazada entre el monte y un estero.

El capitán Solari con sus catalejos observa las huestes de indios y comenta que estaban vacías. Un sargento -Arce- sin embargo le advierte la necesidad de prevenir un ataque de sorpresa, insistiendo en que se tengan las armas desenfundadas.

Cuando la columna llega a las tolderías, una cerrada descarga de armas de fuego salió desde un monte cercano, luego de un primer tiro de escopeta, que en definitiva sería el que hiriera de muerte al capitán Solari. El sargento Arce, también herido, corrió no obstante en auxilio de su jefe. Una vez en tierra se parapeta detrás del caballo de Solari también muerto, y con la pistola del jefe trata de ofrecer resistencia a los indios. Pero herido Arce sólo puede efectuar una retirada, pero sin poder llevar el cadáver de su jefe. ${ }^{50}$

70 Según la otra versión, una vez producido el ataque, herido Arce y muerto Solari, uno de los soldados tomó el control del escuadrón y ordenó la retirada, abandonado a su capitán, al cual supuestamente los indígenas ya estaban desvistiendo para apropiarse de su ropa. Por orden del jefe del Regimiento, coronel Mariano Aráoz de Lamadrid se formó una tropa y se encomendó al teniente José María Ruda regresar a buscar el cuerpo del capitán, acompañado de un pelotón de 40 hombres, de acuerdo a la peligrosidad expresada en el relato anterior. El cuerpo fue encontrado un día después, semisumergido en las aguas de un estero, desnudo y en estado de descomposición. Se lo trasladó a Presidencia Roca, 
donde se lo veló con honores militares. Tiempo después sus restos fueron enviados a Puerto Bermejo y embarcados hasta Corrientes, sitio en el que aún permanecen (López Piacentini 1979).

71 Seis meses después, en octubre de 1912, una comisión del $7^{\circ}$ Regimiento que iba rumbo a Formosa encontró a un indígena vestido con la chaqueta del capitán. Cuando el sargento Félix Benítez lo interpeló sobre la procedencia de la prenda, fue herido de bala fatídicamente. Desde Presidencia Roca se envió entonces una nueva comisión de 50 hombres a cargo del mayor Marcos Hermelo, en busca de los indígenas, muchos de los cuales fueron asesinados y otros tantos tomados prisioneros. Según Cúndom:

[E]l castigo que infligió a los indios, presuntos matadores de Solari, sólo puede parangonarse con una horrible masacre. El mismo mayor Hermelo -en valiente lidia- mató al Cacique Coyaiquí de una estocada en el corazón y sus soldados partían como zapallos el cráneo de los bárbaros que, escribían con el rojo intenso de su sangre el último capítulo de sus eternos infortunios. ${ }^{51}$

La mención al cacique Coyaiquí en esta versión genera una serie de interrogantes, que se suman a la ausencia de nombres propios en los relatos anteriores. Por otro lado, la Memoria escrita por el conscripto Santiago -que parece ser la mención más precisa sobre el asesinato de Illiri en relación a la muerte de Solari y coincidente además con el destino de sus restos- no coincide con la fecha que indica Guerrero para la muerte del cacique (1912), en tanto el conscripto se habría incorporado a las filas recién en 1913, según su propio relato. Estas contradicciones nos obligan a señalar que la información sobre el cacique -así como sobre otros jefes indígenas de la zona- es escasa, incompleta o poco fiable, lo que conlleva una serie de consecuencias, en términos metodológicos. En este sentido, nuestra indagación continúa con el objetivo de poder despejar las dudas que aquí se han indicado.

73 Ahora bien, un último documento encontrado resulta central para el propósito de este artículo. Nos referimos a una fotografía del cacique Illiri reproducida en la memoria descriptiva realizada por el mismo Pedro Cenóz, publicada bajo el título El Gran Chaco (Ver imagen 2). Nos interesa destacar que, más allá de los fragmentos de información faltantes, este hallazgo constituye un importante logro en nuestro intento de recuperar aspectos personales del cacique que -como otros-fue desubjetivizado al ser convertido en objeto de interés antropológico. La imagen fotográfica nos permite re-encontrarnos en forma directa con el cacique, silenciado primero por las armas y después por la ciencia. El relato adquiere corporalidad, el nombre se asocia a una imagen concreta y surge la persona. Illiri, cuyos restos mortales creemos aún se conservan como parte de las colecciones del Museo Etnográfico, permite ser conocido así a través de su propio rostro. 


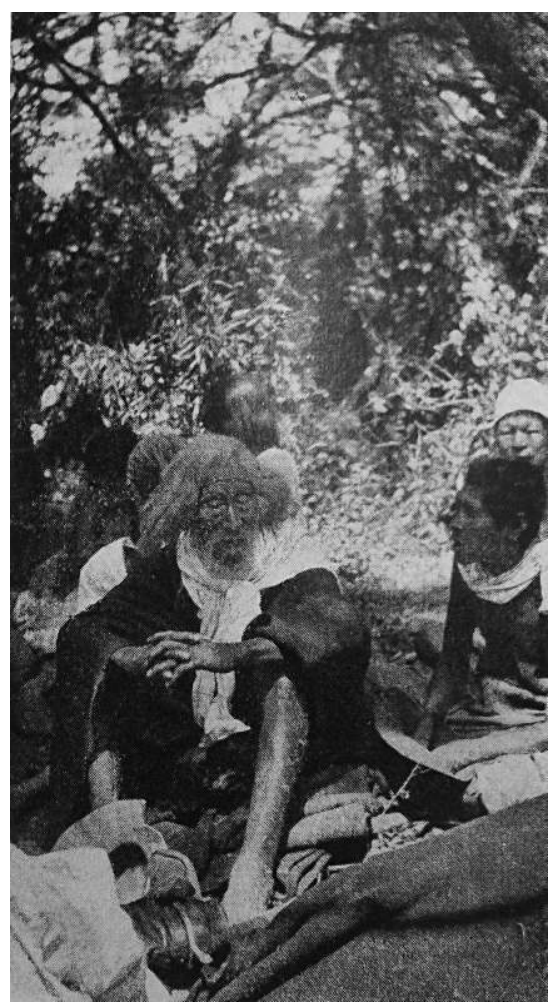

Imagen 2. Cacique Illirí. Fuente: Cenóz (1913).

\section{Reflexiones finales}

Hemos planteado cómo el destacado rol de Ambrosetti en la sistematización, metodologización y profesionalización de la disciplina antropológica en el país (Cáceres Freyre 1967) lo resguardó, por lo menos en parte, de cuestionamientos demasiado críticos respecto de sus modalidades de trabajo. En este sentido, ciertas formas de adquisición de material para el armado y ampliación de las colecciones del Museo Etnográfico merecen ser revisadas y contextualizadas en el marco de otras similares, llevadas a cabo por actores e instituciones que sí han sido objeto de mayores cuestionamientos.

La información de las fuentes presentadas permite constatar el ingreso al Museo Etnográfico, durante el mandato de Ambrosetti, de una serie de restos mortales de indígenas contemporáneos procedentes de territorios recientemente anexados a la nación por medio de campañas militares. El vínculo trazado por el director con instituciones como la Dirección de Territorios Nacionales muestra cómo se viabilizaban los pedidos, convalidados por el marco estatal. Pero es en particular el ingreso de restos humanos procedentes del Gran Chaco, en el mismo momento en que los pueblos originarios estaban siendo diezmados, lo que permite problematizar la relación, fomentada por el mismo Ambrosetti, entre este museo universitario y el Ejército. El minucioso trabajo de archivo y el cruce de documentos conservados en diferentes acervos nos permitió comprobar el ingreso de por lo menos quince cráneos y dieciséis esqueletos completos provenientes solo de esta región, sin enumerar los que constatamos ingresaron con otras procedencias, como ser de la Patagonia.

76 En particular, los casos de Carayá e Illirí ponen de manifiesto que algunos de los jefes indígenas chaqueños muertos durante las campañas militares se incorporaron a las 
colecciones del Museo Etnográfico, de modo similar al caso del Museo de La Plata con los restos de los caciques de Pampa y Patagonia y algunos de sus familiares - como Inacayal y su esposa, Margarita Foyel (hija del cacique Foyel) y Panguitruz Güor-. Asimismo, se destacó también que en el Etnográfico los restos humanos se mantuvieron fuera del alcance visual del público visitante, "invisibles" a los ojos de quienes no se dedicaban a la investigación. Consideramos que no es casual que solo los restos mortales de los dos caciques chaqueños fueran enviados con una identificación precisa, por los propios miembros del Ejército, en tanto este acto parecía expresar el triunfo de la "civilización sobre la barbarie", una demostración de que aquella tierra considerada como indómita había sido por fin dominada.

Por otro lado, a partir de los casos abordados concluimos que este tipo de prácticas de adquisición de restos mortales de indígenas - promovidas por los museos antropológicos, movilizadas por vías institucionales y concretadas con la colaboración de los miembros del Ejército- no eran exclusivas de ningún museo o institución antropológica en particular sino más bien constitutivo de todos ellos. En este sentido, tampoco se circunscribieron exclusivamente al Museo de La Plata, cuyos casos han tenido mayor notoriedad sobre todo en los últimos años. Consideramos, por lo tanto, que el examen de situaciones particulares puede contribuir a una lectura más amplia y completa de las prácticas antropológicas, así como de la compleja relación entre ciencia y aparato represivo del Estado en los albores del siglo XX, en un contexto de marcada violencia contra los pueblos originarios. Finalmente, esperamos que el aporte de datos sobre casos específicos y hasta ahora poco conocidos, permita continuar avanzando en la recuperación de las historias particulares de quienes al ingresar a museos e instituciones antropológicas perdieron todo rasgo de subjetividad. En última instancia, esto posibilitará que los restos que sean identificados puedan volver a su lugar de origen, si así lo decidieran sus descendientes.

Tabla de ingresos de objetos etnográficos y restos humanos al Museo Etnográfico de la región del Gran Chaco ${ }^{52}$

\begin{tabular}{|c|c|c|c|c|c|}
\hline $\begin{array}{l}\text { Año } \\
\text { ingreso }\end{array}$ & $\begin{array}{l}\text { Catalogación } \\
\text { original }\end{array}$ & Procedencia & Descripción & Remitente & Fuente \\
\hline 1906 & 314 a 319 & Pilcomayo, Chaco & $\begin{array}{lcc}2 & \text { juegos } & \text { de } \\
\text { flechas } & \\
2 & \text { corazas } & \text { de } \\
\text { guerra } & \\
2 & \text { bolsas } & \text { de } \\
\text { caraguatá } & \end{array}$ & $\begin{array}{l}\text { Juan Manuel } \\
\text { Ezcurra }\end{array}$ & $\begin{array}{l}\text { AFDME: } \\
\text { Memoria } \\
\text { 1906-1912/ } \\
\text { AGFFyL: Caja } \\
\text { B-5-10, Doc. } \\
\text { 9. }\end{array}$ \\
\hline 1906 & $\begin{array}{l}\text { No se } \\
\text { menciona }\end{array}$ & Chaco & $\begin{array}{l}1 \text { cántaro de } \\
\text { alfarería de los } \\
\text { indios toba } \\
\text { recogido en una } \\
\text { toldería } \\
\text { abandonada }\end{array}$ & $\begin{array}{l}\text { Guillermo } \\
\text { Navarro }\end{array}$ & $\begin{array}{l}\text { AGFFyL: } \\
\text { Caja B-5-10, } \\
\text { Doc. } 13 .\end{array}$ \\
\hline
\end{tabular}




\begin{tabular}{|c|c|c|c|c|c|}
\hline 1907 & 2447 & $\begin{array}{l}\text { Fortín Tostado. } \\
\text { Chaco santafesino }\end{array}$ & $\begin{array}{l}1 \text { cráneo de } \\
\text { Indio Mocoví } \\
2 \quad \text { objetos } \\
\text { etnográficos } \\
\text { (mate relleno de } \\
\text { plomo y forma } \\
\text { de plomo para } \\
\text { boleadora) }\end{array}$ & $\begin{array}{l}\text { Dr. Teófilo } \\
\text { Weschler }\end{array}$ & $\begin{array}{l}\text { AFDME: } \\
\text { Memoria } \\
\text { 1906-1912/ } \\
\text { AGFFyL: } \\
\text { Caja B-5-10, } \\
\text { Doc. 60. }\end{array}$ \\
\hline 1909 & 6612 a 6615 & Ledesma, Jujuy & $\begin{array}{l}4 \text { esqueletos de } \\
\text { indios } \\
\text { chiriguanos del } \\
\text { chaco boliviano }\end{array}$ & $\begin{array}{ll}\text { Dr. Juan } \\
\text { Paglia }\end{array}$ & $\begin{array}{l}\text { AFDME: } \\
\text { Legajo de } \\
\text { colecciones } \\
\text { № 19, J. } \\
\text { Paglia y } \\
\text { Memoria } \\
\text { 1906-1912/ } \\
\text { AGFFyL: } \\
\text { Caja B-5-10, } \\
\text { Doc.71. }\end{array}$ \\
\hline 1909 & 6858 a 6885 & Chaco Austral & 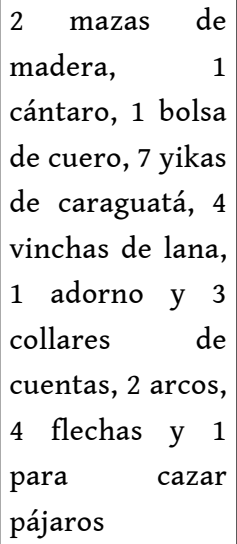 & $\begin{array}{l}\text { Mayor Pedro } \\
\text { Cenóz }\end{array}$ & $\begin{array}{l}\text { AFDME: } \\
\text { Memoria } \\
\text { 1906-1912 y } \\
\text { Documentos } \\
\text { de } \\
\text { colecciones } \\
\mathrm{N}^{\circ} \quad \text { III/ } \\
\text { AGFFyL: Caja } \\
\text { B-5-10 Doc. } \\
72 .\end{array}$ \\
\hline 1909 & $\begin{array}{l}6919 / \\
6920\end{array}$ & Resistencia, Chaco & $\begin{array}{l}1 \text { cráneo toba y } \\
\text { unas cuantas } \\
\text { flechas, } \\
\text { y un juego de } \\
\text { arco y flechas de } \\
\text { los indios tobas }\end{array}$ & $\begin{array}{l}\text { Tte. Coronel } \\
\text { Francisco M. } \\
\text { Guerrero }\end{array}$ & $\begin{array}{l}\text { AFDME: } \\
\text { Legajo de } \\
\text { colecciones } \\
\text { № 18, F. M. } \\
\text { Guerrero; } \\
\text { Memoria } \\
\text { 1906-1912 y } \\
\text { Documentos } \\
\text { de } \\
\text { colecciones } \\
N^{\circ} \\
\text { AGFFyL: Caja } \\
\text { B-5-10, Doc. } \\
77\end{array}$ \\
\hline
\end{tabular}




\begin{tabular}{|c|c|c|c|c|c|}
\hline 1909 & $\begin{array}{l}\text { No se } \\
\text { menciona }\end{array}$ & $\begin{array}{l}\text { Chaco jujeño, entre } \\
\text { San Pedro de Jujuy y } \\
\text { Calilegua. Ingenio } \\
\text { Ledesma }\end{array}$ & $\begin{array}{l}348 \text { objetos } \\
\text { etnográficos de } \\
\text { los indios } \\
\text { chiriguanos, } \\
\text { matacos, } \\
\text { chulupíes y } \\
\text { chorotes, entre } \\
\text { ellas arcos, } \\
\text { flechas } \\
\text { instrumentos de } \\
\text { agricultura, } \\
\text { yikas, pipas, } \\
\text { silbatos de } \\
\text { guerra, vinchas, } \\
\text { etc. }\end{array}$ & $\begin{array}{l}\text { Expedición de } \\
\text { la } \quad \text { FFyL- } \\
\text { Debenedetti }\end{array}$ & $\begin{array}{l}\text { AGFFyL: } \\
\text { Caja B-5-10, } \\
\text { Doc. } 64 \text { y } 65\end{array}$ \\
\hline 1909 & $\begin{array}{l}\text { No se } \\
\text { menciona }\end{array}$ & $\begin{array}{l}\text { Chaco boliviano } \\
\text { y Bolivia }\end{array}$ & $\begin{array}{l}\text { Más de } 230 \\
\text { objetos } \\
\text { arqueológicos y } \\
\text { etnográficos }\end{array}$ & $\begin{array}{l}\text { Colección } \\
\text { comprada a } \\
\text { Eduardo } \\
\text { Holmberg (h) }\end{array}$ & $\begin{array}{l}\text { AFDME: } \\
\text { Legajo de } \\
\text { colecciones } \\
\mathrm{N}^{\circ} \quad 46, \quad \mathrm{E} . \\
\text { Holmberg (h) }\end{array}$ \\
\hline 1911 & 8473 & Alto Paraguay & $\begin{array}{l}1 \text { arco y seis } \\
\text { flechas de los } \\
\text { indios guatos }\end{array}$ & Juan Roth & $\begin{array}{l}\text { AGFFyL: } \\
\text { Caja B-5-10, } \\
\text { Doc. } 93\end{array}$ \\
\hline $1911^{53}$ & 8881 & Chaco & $\begin{array}{lr}\text { Cráneo } & \text { de } \\
\text { indio } & \text { toba } \\
\text { (cacique } & \\
\text { Carayá) } & \end{array}$ & $\begin{array}{l}\text { Museo } \\
\text { Nacional de } \\
\text { Bellas Artes. } \\
\text { Autorizado } \\
\text { por Ministerio } \\
\text { de Instrucción } \\
\text { Pública }\end{array}$ & $\begin{array}{l}\text { AFDME: } \\
\text { Memoria } \\
\text { 1906-1912 }\end{array}$ \\
\hline 1911 & 9597 & Chaco & $\begin{array}{lrr}1 \text { arco } & \text { y } & \text { un } \\
\text { juego } & \text { de } & 8 \\
\text { flechas de } & \text { los } \\
\text { indios matacos }\end{array}$ & $\begin{array}{l}\text { Ingeniero } \\
\text { Livio Castilla }\end{array}$ & $\begin{array}{l}\text { AFDME: } \\
\text { Memoria } \\
\text { 1906-1912/ } \\
\text { AGFFyL: } \\
\text { Caja B-5-10, } \\
\text { Doc. } 100\end{array}$ \\
\hline 1911 & $\begin{array}{l}10719 \\
10721\end{array}$ & Chaco & 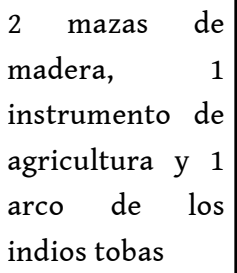 & $\begin{array}{l}\text { Alberto } \\
\text { Escalada }\end{array}$ & $\begin{array}{l}\text { AFDME: } \\
\text { Memoria } \\
1906-1912\end{array}$ \\
\hline
\end{tabular}




\begin{tabular}{|c|c|c|c|c|c|}
\hline 1911 & $\begin{array}{l}10643 \quad a \\
10681\end{array}$ & Paraguay & $\begin{array}{l}\text { Colección étnica } \\
\text { de } 38 \text { piezas de } \\
\text { las } \\
\text { tribus guayakí y } \\
\text { kainguá del } \\
\text { Paraguay }\end{array}$ & Luis Patri & $\begin{array}{l}\text { AGFFyL: } \\
\text { Caja B-5-10, } \\
\text { Doc. } 105\end{array}$ \\
\hline 1911 & $\begin{array}{l}10805 \quad a \\
10823\end{array}$ & Alto Paraná & $\begin{array}{l}\text { Colección de } 19 \\
\text { objetos de los } \\
\text { indios guayakíes }\end{array}$ & $\begin{array}{l}\text { Berta } \\
\text { Wernicke }\end{array}$ & $\begin{array}{l}\text { AGFFYL: } \\
\text { Caja B-5-10, } \\
\text { Doc. } 109\end{array}$ \\
\hline 1911 & $\begin{array}{l}11258 \quad a \\
11260\end{array}$ & Chaco & $\begin{array}{l}1 \text { faja tejida de } \\
\text { indio toba, } \\
2 \text { objetos de } \\
\text { indios matacos }\end{array}$ & $\begin{array}{l}\text { Srta. Victoria } \\
\text { Aguirre }\end{array}$ & $\begin{array}{l}\text { AFDME: } \\
\text { Memoria } \\
\text { 1906-1912 }\end{array}$ \\
\hline 1911 & $\begin{array}{l}\text { No se } \\
\text { menciona }\end{array}$ & $\begin{array}{l}\text { Alto Parana "Chaco } \\
\text { Paraguayo" }\end{array}$ & $\begin{array}{l}22 \text { piezas de los } \\
\text { indios } \\
\text { guayaquíes, } \\
\text { entre ellas un } \\
\text { hacha de piedra } \\
\text { con mango de } \\
\text { madera. }\end{array}$ & $\begin{array}{l}\text { Federico } \\
\text { Mayntzhusen }\end{array}$ & $\begin{array}{l}\text { AGFFyL: } \\
\text { Caja B-5-10, } \\
\text { Doc. } 95\end{array}$ \\
\hline 1911 & $\begin{array}{l}\text { No se } \\
\text { menciona }\end{array}$ & Río Paraguay & $\begin{array}{l}53 \text { objetos de los } \\
\text { indios } \\
\text { chamacocos }\end{array}$ & Alberto V. Fric & $\begin{array}{l}\text { AGFFyL: } \\
\text { Caja B-5-10, } \\
\text { Doc. } 94\end{array}$ \\
\hline 1912 & 12698 & $\begin{array}{l}\text { Formosa objeto } \\
\text { encontrado en la } \\
\text { margen derecha del } \\
\text { Rio Pilcomayo, en el } \\
\text { paraje denominado } \\
\text { Puerto del Dorado a } \\
\text { tres leguas del Fortín } \\
\text { Yunká }\end{array}$ & $\begin{array}{l}1 \text { hacha de } \\
\text { piedra }\end{array}$ & $\begin{array}{l}\text { Tte. Coronel } \\
\text { Francisco M. } \\
\text { Guerrero }\end{array}$ & $\begin{array}{l}\text { AFDME: } \\
\text { Legajo de } \\
\text { colecciones } \\
\text { № 18, F. M. } \\
\text { Guerrero y } \\
\text { Documentos } \\
\text { de } \\
\text { colecciones } \\
\mathrm{N}^{\circ} \text { III }\end{array}$ \\
\hline 1912 & $\begin{array}{l}12700 \\
12713\end{array}$ & Chaco & $\begin{array}{ll}14 & \text { objetos } \\
\text { uso } & \text { personal de } \\
\text { los } & \text { indios } \\
\text { pilagás } & \end{array}$ & $\begin{array}{l}\text { Capitán } \\
\text { Alberto } \\
\text { Benavídez }\end{array}$ & $\begin{array}{l}\text { AGFFyL: Caja } \\
\text { B-5-11, Doc. } 4\end{array}$ \\
\hline 1912 & $12700 / 713$ & Chaco y Formosa & Arcos y flechas & $\begin{array}{l}\text { Tte. Coronel } \\
\text { Francisco M. } \\
\text { Guerrero }\end{array}$ & $\begin{array}{l}\text { AFDME: } \\
\text { Documentos } \\
\text { de } \\
\text { colecciones } \\
\mathrm{N}^{\circ} \text { III }\end{array}$ \\
\hline
\end{tabular}




\begin{tabular}{|c|c|c|c|c|c|}
\hline 1913 & $\begin{array}{ll}13.339 & a \\
13.400 & \end{array}$ & Chaco & $\begin{array}{l}1 \text { poncho toba, } 1 \\
\text { limita hecha de } \\
\text { piedra/ } 1 \text { cajón } \\
\text { con objetos } \\
\text { indígenas tobas } \\
\text { cuya lista se } \\
\text { acompaña (no } \\
\text { se encuentra en } \\
\text { el legajo) }\end{array}$ & $\begin{array}{l}\text { Misión } \\
\text { Enrique Lynch } \\
\text { Arribálzaga }\end{array}$ & $\begin{array}{l}\text { AFDME: } \\
\text { Legajo de } \\
\text { colecciones } \\
\text { № 60, Lynch } \\
\text { Arribálzaga }\end{array}$ \\
\hline 1913 & $\begin{array}{l}13.778 \mathrm{a} \\
13.818\end{array}$ & Chaco & $\begin{array}{l}1 \text { "esqueletito } \\
\text { de india toba" } \\
\text { y objetos de los } \\
\text { indios pilagás }\end{array}$ & $\begin{array}{l}\text { Tte. Coronel } \\
\text { Francisco M. } \\
\text { Guerrero }\end{array}$ & $\begin{array}{l}\text { AFDME: } \\
\text { Legajo de } \\
\text { colecciones } \\
\mathrm{N}^{2} \quad 18, \quad \mathrm{~F} . \\
\text { Guerrero y } \\
\text { Documentos } \\
\text { de } \\
\text { colecciones } \\
\mathrm{N}^{\circ} \text { III }\end{array}$ \\
\hline 1913 & 14.442 & Chaco & $\begin{array}{l}1 \text { cráneo de } \\
\text { indio }\end{array}$ & $\begin{array}{l}\text { Libia E. de } \\
\text { Holmberg }\end{array}$ & $\begin{array}{l}\text { AFDME: } \\
\text { Legajo de } \\
\text { colecciones } \\
\text { № } 52 \text {, Libia } \\
\text { de Holmberg } \\
\text { y } \\
\text { Documentos } \\
\text { de } \\
\text { colecciones } \\
\mathrm{N}^{\circ} \text { III }\end{array}$ \\
\hline 1913 & $\begin{array}{l}15.421 \\
15.475\end{array}$ & Chaco & $\begin{array}{l}1 \text { pala toba, arco } \\
\text { y flechas }\end{array}$ & $\begin{array}{l}\text { Misión } \\
\text { Enrique Lynch } \\
\text { Arribálzaga }\end{array}$ & $\begin{array}{l}\text { AFDME: } \\
\text { Legajo de } \\
\text { colecciones } \\
\text { № 60, Misión } \\
\text { L. } \\
\text { Arribálzaga }\end{array}$ \\
\hline 1913 & $\begin{array}{l}15.482 \\
15.483\end{array}$ & 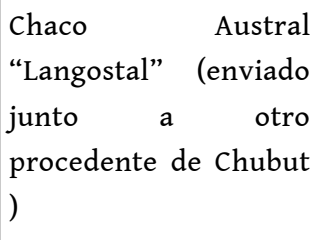 & $\begin{array}{l}1 \text { cráneos } \\
\text { humano }\end{array}$ & $\begin{array}{l}\text { Prof. Juan A. } \\
\text { Domínguez }\end{array}$ & $\begin{array}{l}\text { AFDME: } \\
\text { Documentos } \\
\text { de } \\
\text { colecciones } \\
\mathrm{N}^{\circ} \mathrm{III}\end{array}$ \\
\hline 1913 & $\begin{array}{l}\text { No se } \\
\text { menciona }\end{array}$ & Chaco y Neuquén & $\begin{array}{l}17 \text { objetos no } \\
\text { identificados }\end{array}$ & $\begin{array}{l}\text { Jorge } \\
\text { González } \\
\text { Larrosa }\end{array}$ & $\begin{array}{l}\text { AFDME: } \\
\text { Memoria } \\
\text { 1913-1914 }\end{array}$ \\
\hline
\end{tabular}




\begin{tabular}{|c|c|c|c|c|c|}
\hline 1914 & $\begin{array}{l}16136 \\
16137\end{array}$ & Formosa & $\begin{array}{l}\text { Esqueleto del } \\
\text { cacique Illiri y } \\
\text { de su hijo }\end{array}$ & $\begin{array}{l}\text { Tte. Coronel } \\
\text { Francisco M. } \\
\text { Guerrero }\end{array}$ & $\begin{array}{l}\text { AFDME: } \\
\text { Legajo de } \\
\text { colecciones } \\
\text { № 18, F. M. } \\
\text { Guerrero; } \\
\text { Documentos } \\
\text { de } \\
\text { colecciones } \\
\mathrm{N}^{\circ} \quad \text { III } \\
\text { Memoria } \\
\text { 1913-1914/ } \\
\text { AGFFYL: } \\
\text { Caja B-5-11, } \\
\text { Doc. 7 }\end{array}$ \\
\hline $\begin{array}{l}1914 \\
1915\end{array}$ & $\begin{array}{l}16696 / 17016 \\
20744 / 45\end{array}$ & Chaco & $\begin{array}{l}\text { Objetos } \\
\text { etnográficos de } \\
\text { los indios tobas } \\
2 \text { objetos tobas }\end{array}$ & $\begin{array}{l}\text { Misión } \\
\text { Enrique Lynch } \\
\text { Arribálzaga }\end{array}$ & $\begin{array}{l}\text { AFDME: } \\
\text { Documentos } \\
\text { de } \\
\text { colecciones } \\
\mathrm{N}^{\circ} \mathrm{III}\end{array}$ \\
\hline 1914 & 17.053 & Chaco & $\begin{array}{l}1 \text { cráneo } \\
\text { humano }\end{array}$ & $\begin{array}{l}\text { Carlos } \\
\text { Brackebusch }\end{array}$ & $\begin{array}{l}\text { AFDME: } \\
\text { Documentos } \\
\text { de } \\
\text { colecciones } \\
\mathrm{N}^{\circ} \quad \text { III } \quad \mathrm{y} \\
\text { Memoria } \\
\text { 1914-15 }\end{array}$ \\
\hline 1914 & 17219 & Napalpí, Chaco & $\begin{array}{ll}1 & \text { cráneo } \\
\text { humano toba }\end{array}$ & $\begin{array}{l}\text { Hipólito } \\
\text { Poyssegur }\end{array}$ & $\begin{array}{l}\text { AFDME: } \\
\text { Memoria } \\
\text { 1914-15 }\end{array}$ \\
\hline $\begin{array}{l}1914 \\
1914 \\
1915\end{array}$ & $\begin{array}{l}17718 \\
17719 \\
19063 \\
19069 \\
19971\end{array}$ & $\begin{array}{l}\text { Formosa } \\
\text { Chaco Austral } \\
\text { Río de Oro, Chaco }\end{array}$ & $\begin{array}{l}\text { Esqueletos } \\
\text { humanos } \\
\text { indios toba } \\
\text { Objetos de } \\
\text { indios tobas y } \\
\text { esqueleto } \\
\text { humano } \\
\text { Esqueleto de } \\
\text { mujer toba } \\
\text { Esqueleto } \\
\text { humano indio } \\
\text { toba }\end{array}$ & $\begin{array}{l}\text { Misión Luis } \\
\text { González } \\
\text { Leyva }\end{array}$ & $\begin{array}{l}\text { AFDME: } \\
\text { Documentos } \\
\text { de } \\
\text { colecciones } \\
\mathrm{N}^{\circ} \text { III y } \\
\text { Memoria } \\
\text { 1914-1915 }\end{array}$ \\
\hline 1914 & $\begin{array}{l}\text { No se } \\
\text { menciona }\end{array}$ & Chaco & No identificados & $\begin{array}{l}\text { Alberto } \\
\text { Escalada }\end{array}$ & $\begin{array}{l}\text { AFDME: } \\
\text { Memoria } \\
\text { 1914-15 }\end{array}$ \\
\hline
\end{tabular}




\begin{tabular}{|c|c|c|c|c|c|}
\hline - & $\begin{array}{l}\text { No se } \\
\text { menciona }\end{array}$ & $\begin{array}{l}\text { Chaco, Jujuy } \quad \text { y } \\
\text { Paraguay }\end{array}$ & No identificados & $\begin{array}{l}\text { Salvador } \\
\text { Debenedetti }\end{array}$ & $\begin{array}{l}\text { AFDME: } \\
\text { Memoria } \\
1916\end{array}$ \\
\hline 1915 & $\begin{array}{ll}\text { No se } \\
\text { menciona }\end{array}$ & Resistencia & $\begin{array}{l}\text { Pala, arcos y } \\
\text { flechas } \\
\text { realizadas por } \\
\text { un anciano toba }\end{array}$ & $\begin{array}{l}\text { Misión Lynch } \\
\text { Arribálzaga }\end{array}$ & $\begin{array}{l}\text { AFDME: } \\
\text { Legajo de } \\
\text { Colecciones } \\
\mathrm{N}^{\circ} 60 \text {, Misión } \\
\text { L. } \\
\text { Arribálzaga }\end{array}$ \\
\hline 1915 & $\begin{array}{l}\text { No se } \\
\text { menciona }\end{array}$ & Chaco & No identificados & $\begin{array}{l}\text { Alfonso } \\
\text { Najera }\end{array}$ & $\begin{array}{l}\text { AFDME: } \\
\text { Memoria } \\
1916\end{array}$ \\
\hline 1915 & $\begin{array}{l}\text { No se } \\
\text { menciona }\end{array}$ & $\begin{array}{l}\text { Chaco argentino y } \\
\text { boliviano }\end{array}$ & No identificados & $\begin{array}{l}\text { Cristobal } \\
\text { Hicken }\end{array}$ & $\begin{array}{l}\text { AFDME: } \\
\text { Memoria } \\
1916\end{array}$ \\
\hline 1915 & $\begin{array}{l}\text { No se } \\
\text { menciona }\end{array}$ & Chaco & No identificados & $\begin{array}{l}\text { Isaac } \\
\text { Fernández } \\
\text { Blanco }\end{array}$ & $\begin{array}{l}\text { AFDME: } \\
\text { Memoria } \\
1916\end{array}$ \\
\hline 1915 & $\begin{array}{l}\text { No se } \\
\text { menciona }\end{array}$ & Chaco & No identificado & $\begin{array}{l}\text { Misión. Sergei } \\
\text { Geiman }\end{array}$ & $\begin{array}{l}\text { AFDME: } \\
\text { Memoria } \\
1916\end{array}$ \\
\hline 1915 & $\begin{array}{l}\text { No se } \\
\text { menciona }\end{array}$ & Chaco salteño & $\begin{array}{l}1 \text { Esqueleto de } \\
\text { indio pilagá de } \\
\text { los que tienen el } \\
\text { rito fúnebre de } \\
\text { poner sus } \\
\text { cadáveres sobre } \\
\text { los árboles, } \\
8 \text { cráneos de } \\
\text { indios matacos } \\
\text { y chiriguanos }\end{array}$ & $\begin{array}{l}\text { Misión Juan } \\
\text { Ascher }\end{array}$ & $\begin{array}{l}\text { AFDME: } \\
\text { Memoria } \\
\text { 1916/ } \\
\text { AGFFyL: Caja } \\
\text { B-5-11, Doc. } \\
24\end{array}$ \\
\hline 1916 & $\begin{array}{l}\text { No se } \\
\text { menciona }\end{array}$ & Chaco & $\begin{array}{l}3 \text { esqueletos de } \\
\text { indios tobas }\end{array}$ & $\begin{array}{l}\text { Ulpiano } \\
\text { Cáceres }\end{array}$ & $\begin{array}{l}\text { AFDME: } \\
\text { Memoria } \\
1916 \\
\text { AGFFyL: Caja } \\
\text { B-5-11, } \\
\text { Doc.23 }\end{array}$ \\
\hline
\end{tabular}

\section{Listado de abreviaturas}

AGN: Archivo General de la Nación 
AGFFyL: Archivo General de la Facultad de Filosofía y Letras

AFDME: Archivo Fotográfico y Documental del Museo Etnográfico Juan B. Ambrosetti

\section{Fuentes}

AGN

AGFFyL

AFDME

\section{BIBLIOGRAPHY}

Ambrosetti, J. B. (2005). Viaje de un maturrango y otros relatos folklóricos. Buenos Aires: Taurus.

Ambrosetti, J. B. (2008). Primer y segundo viaje a misiones. Buenos Aires: Editorial Albatro.

Arenas, P. (1989). La antropología en la Argentina de fines del Siglo XIX y principios del XX. Runa, $2,89-104$

Arenas, P. y Pinedo J. (noviembre 2005). Damiana vuelve a los suyos. Página 12 [On Line]. Disponible http://www.pagina12.com.ar/diario/suplementos/radar/9-2639-2005-11-21.html

Arias, A. C. y Dávila, L. (primavera 2014). Prácticas de viaje y autoridad científica. Una comparación de experiencias de D’Orbigny, Ambrosetti y Lehmann-Nitsche [On line]. Revista de Ciencias Sociales, 26. Universidad Nacional de Quilmes. Disponible: http://www.unq.edu.ar/ catalogo/348- revista-de-ciencias-sociales-n-26.php11

Badenes, D. (septiembre 2006). Restos humanos en el Museo de Ciencias Naturales de La Plata, Revista La Pulseada, 43, septiembre de 2016. [On Line] Disponible: http:// www.lapulseada.com.ar/43/43_museo.html

Beck, H. H. (1994). Relaciones entre blancos e indios en los territorios nacionales de chaco y Formosa. 1885-1950 Cuadernos de Geohistoria Regional, 29, 7-209.

Brunatti, O., Colángelo M. y Soprano G. (2002) Observar para legislar En S. Visacovsky y R. Guber (comp.) Historias y estilos de trabajo de campo en Argentina (pp. 79-123). Rosario: Editorial Antropofagía.

Cáceres Freyre, J. (1967). Juan Bautista Ambrosetti. Buenos Aires: Ediciones Culturales Argentinas.

Cenóz, P. (1913). El Chaco Argentino. Buenos Aires: Talleres de la casa Jacobo Peuser.

Chébez, J. C. Y Gasparri B. (2008). Presentación de primer y segundo viaje a Misiones por Juan Bautista Ambrosetti. En J. B. Ambrosetti, Primer y segundo Viaje a Misiones (pp. 12-14). Buenos Aires: Editorial Albatros.

Colectivo Guías (2008). Identificación y restitución: “Colecciones" de restos humanos en el Museo de La Plata. La Plata: Huellas.

Cúndom, F. P. (1962). La tragedia del Capitán Solari. Una breve versión. En C. P. López Piacentini, (1979) Historia de la Provincia del Chaco (Tomo 3, pp. 94- 97). Chaco : Editorial región. 
Curtoni, R. P. y Chaparro, M. G. (2011). Políticas de reparación: Reclamación y reentierro de restos indígenas. El caso de Gregorio Yancamil , Corpus I (1). [On line] Disponible: http:// corpusarchivos.revues.org/931; DOI : 10.4000/corpusarchivos.931.

De Marco, M. A. (2003). Apuntes de un ex soldado conscripto durante la Campaña del Chaco. Temas de historia argentina y americana, 2, 211-220.

Farro, M. E. (2009). La formación del Museo de La Plata. Coleccionistas, comerciantes, estudiosos y naturalistas viajeros a fines Del Siglo XIX. Rosario: Prohistoria Ediciones.

Foucault, M. (2001) Vigilar y castigar. Nacimiento de La Prisión. México: Siglo XXI.

González Stephan, B. (1999). Cuerpos de La Nación: Cartografías Disciplinarias. Anales, II, s/p.

Gordillo, G. (1995). La subordinación y sus mediaciones: Dinámica cazadora-recolectora, relaciones de producción, capital comercial y estado entre los tobas del Oeste de Formosa (s/p). En H. H. Trinchero, Producción doméstica y capital: estudios desde la Antropología Económica. Buenos Aires: Biblos.

Gustavsson, A. (2008). Documentation, Research, conservation, restitution and exhibition of human remains collection at university museums in Argentina. The case of the Museo Etnográfico Juan B. Ambrosetti in Buenos Aires. Master Dissertation in International Museum Studies. Museion, Gottenburg University.

Gustavsson, A. (junio 2011) Estrategias del Museo Etnográfico J. B. Ambrosetti frente a la restitución de restos humanos, Corpus I (1). [On line] Disponible: http:// corpusarchivos.revues.org/950

Iñigo Carreras, N. (1984) Indígenas y fronteras. Campañas militares y clase obrera. Chaco, 1870-1930. Buenos Aires: Centro Editor de América Latina.

Lynch Arribálzaga, E. (1924) Materiales para una bibliografía de Chaco y Formosa, Resistencia: Tipográfico Juan Moro.

López Piacentini, C. P. (1979) La Conquista del desierto verde En C. P. López Piacentini, Historia de la Provincia del Chaco (Tomo 3, pp 1-142.). Chaco : Editorial Región.

Mansilla, L. V. (1995) Esa cabeza toba. Horror al vacío y otras charlas. Buenos Aires: Editorial Biblos.

Minnitti Morgan, E. R. (2011). El cacique Inglés. Córdoba: Ediciones Eta Carinae.

Musante, M. (2013). Las reducciones estatales indígenas. ¿Espacios concentracionarios o avance del proyecto civilizatorio? [On line] En Jornadas Santiago Wallace de Investigación en Antropología Social. Facultad de Filosofía y Letras, Universidad de Buenos Aires [On line]. Disponible: http://www.aacademica.org/000-063/359.pdf

Pegoraro, A. (2005) “Instrucciones” y colecciones en viaje. Redes de recolección entre el Museo Etnográfico y los Territorios Nacionales, Anuario de Estudios en Antropología Social, 49-64.

Pegoraro, A. (2009). Las colecciones del Museo Etnográfico de la Universidad de Buenos Aires: un episodio de la historia del americanismo en la Argentina 1890-1927. Tesis doctoral defendida en 2009, Facultad de Filosofía y Letras, Universidad de Buenos Aires.

Pegoraro, A. y Elías M. (2010). Documentación de colecciones etnográficas: los desafíos de los tiempos actuales. El caso de las colecciones etnográficas del Museo Etnográfico Juan B. Ambrosetti de la Universidad de Buenos Aires. $1^{\circ}$ Congreso Nacional de Museos Universitarios, Universidad de La Plata, 20 al 22 de octubre. [On line]. Disponible: http://sedici.unlp.edu.ar/ bitstream/handle/10915/41723/Documento_completo.pdf?sequence=1 
Pegoraro, A. y Spoliansy V. (2013). El Archivo del Museo Etnográfico Juan B. Ambrosetti: documentos para la historia institucional y disciplinar. Revista Electrónica de Fuentes y Archivos Centro de Estudios Históricos "Prof. Carlos S. A. Segreti”, IV (4), 180-189.

Pérez Gollán, J. A. y Pegoraro A. (2004). La repatriación de un Toi Moko. Relaciones de la Sociedad Argentina de Antropología, XXIX, 331-338.

Perazzi, P. (2005). Los Institutos de Investigación de la Facultad de Filosofía y Letras de la Universidad de Buenos Aires: una síntesis de sus acciones, 1896-1975. En Proyectos y actividades de los Institutos de Investigación de la Facultad de Filosofía y Letras (pp. 13-44). Buenos Aires: Universidad de Buenos Aires.

215

Perazzi P. (2011). La antropología en escena: redes de influencia, sociabilidad y prestigio en los orígenes del Museo Etnográfico de la Universidad de Buenos Aires. Anthropologica, XXIX, 215-231.

Rostagno, E. (1969 [1911]). Informes Fuerzas En Operaciones En El Chaco 1911. Buenos Aires: Biblioteca de actualización militar.

Ruiz Moreno, I. (2012). Campañas militares argentinas: luchas contra indios y sediciosos (1878-1884). Buenos Aires: Editorial Claridad

Tamagno, L. (2009). Saberes, ética y política. La restitución de restos humanos en el Museo de La Plata En L. Tamagno (coord.), Pueblos indígenas: interculturalidad, colonialidad y política (pp.105-113). Buenos Aires: Biblos.

Tamagno, L., Maidana, C. Y Martínez, A. (2015) Rebeliones indígenas, movimientos socioreligiosos y procesos de territorialización. El Dios Luciano y la iglesia evangélica unida en Argentina, Tabula Rasa. Bogotá - Colombia, 22, 147-166.

Trinchero, H. H. (2000). Los Dominios del demonio. Buenos Aires: EUDEBA.

Verdesio, G. (2011). Archivos virtuales de la alteridad americana [En línea], Corpus. I (1). [On line] Disponible: http://ppct.caicyt.gov.ar/index.php/corpu

Viyeiro, J. C. (2014). Enrique Lynch Arribálzaga. Benefactor del Chaco, Centro Vasco del Chaco, Chaco. [On line]. Disponible: http://www.vascosdelchaco.com/index.php/component/content/ article/35-vascos-notables/98-enrique-lynch-arribalzaga.html.

\section{NOTES}

1. Pensamientos sobre un dibujo de la cabeza de un guerrero toba de Jorge Luis Fontana, regalado por Mansilla a Avellaneda: "El dibujo adjunto representa la cabeza muerta de un guerrero de la Nación Toba, copiada del natural, momentos antes de ser ella separada del tronco que la sustentara, cuando aún palpitaba la carne y resonaba en mi oído la voz valiente y sonora que, dominando entre el estruendo de las armas y el ardor de la pelea, retemplaba el espíritu de los indios. Olvidaba decirle que el cráneo desecado por mí, de la cabeza a que me refiero, figuró en la última Exposición de la Sociedad Científica, y que hoy se encuentra en el Museo Antropológico de mi amigo Francisco de Paula Moreno" (Carta de Fontana a Mansilla, Villa Occidental, 30 septiembre de 1878, trascrita en Mansilla 1995, p. 198)

2. Agradecemos al Lic. Marcelo Musante por sus aportes y sugerencias, los cuales han sido de gran valor para el presente artículo, a Juan Manuel Cabrera Ventura por el mejoramiento de las imágenes fotográficas y a Maximiliano Albornoz por su especial contribución. Asimismo, a Raúl 
Robles, Jefe del Archivo General de la Facultad de Filosofía y Letras (AGFFyL) y a María Isabel Scarafoni, encargada del Archivo Fotográfico y Documental del Museo Etnográfico Juan B. Ambrosetti (AFDME)

3. Para un mayor desarrollo sobre el Museo de La Plata ver Farro, 2009; sobre el Museo Etnográfico, ver Pegoraro, 2009.

4. A lo largo del artículo empleamos la denominación "restos mortales" por ser la utilizada en la Ley № 25.517 (2003) reglamentada por el Decreto 1022 (2004). Según el Artículo $1^{\circ}$ de dicha Ley, "Los restos mortales de aborígenes, cualquiera fuera su característica étnica, que formen parte de museos y/o colecciones públicas o privadas, deberán ser puestos a disposición de los pueblos indígenas y/o comunidades de pertenencia que lo reclamen". También utilizamos como variante el concepto de "restos humanos". http://www.sdh.gba.gov.ar/comunicacion/ normativanacyprov/pueblosoriginarios/nacional/nac_ley25517.pdf

5. Juan Bautista Ambrosetti (1865-1917) realizó su primer viaje como parte de una expedición militar al Chaco santafesino en 1885 de la mano del capitán A. Romero, del Batallón de Infantería de Marina. Ambos se conocieron en la casa de Eduardo L. Holmberg, en la cual solían realizarse reuniones con reconocidas figuras de la época, entre ellas Enrique Lynch Arribálzaga, a quien nos referiremos más adelante. Unos años después, Ambrosetti realizó visitas a Misiones, ya con el objetivo de recolectar información sobre aquellos territorios. El segundo viaje lo hizo bajo el auspicio del entonces director del Museo de La Plata Francisco P. Moreno, como naturalista viajero de la denominada Expedición Científica al Nordeste (Ambrosetti 2008, Chebez y Gasparri 2008, Arias y Dávila 2014).

6. Parte de esos envíos forman parte de la llamada Colección Toba, que ha merecido un trabajo de catalogación conjunta entre miembros del Museo y de una comunidad qom de Derqui, provincia de Buenos Aires, el cual fue editado en un CD que se distribuyó entre asociaciones, organizaciones e instituciones interesadas (Pegoraro y Elías, 2010.).

7. La región del Gran Chaco comprende el centro sur de Brasil, el oeste de Paraguay, el oriente boliviano y el centro norte de Argentina. Para este trabajo nos hemos centrado en este último sector, correspondiente a Argentina.

8. Memoria elevada por Ambrosetti a Rodolfo Rivarola, decano de la Facultad de Filosofía y Letras, Buenos Aires, 1 de abril de 1915. AFDME, Fondo Ambrosetti.

9. Con autorización de la Facultad. Nota elevada por Ambrosetti a José N. Matienzo, decano de la Facultad de Filosofía y Letras. Buenos Aires, 7 de diciembre de 1907. AGFFyL, Caja B 5-10, Doc. 35.

10. Carta de Ambrosetti a Isidoro Ruiz Moreno, Buenos Aires, 22 de julio de 1915. AGN. Sala VII. Fondo Isidoro Ruiz Moreno, Legajo 5, F. 2.

11. Respuesta de la Gobernación de Misiones, Misiones, 28 de septiembre de 1915. AFDME, Fondo Ambrosetti, Expediente Territorios Nacionales, F. 1, № 401.

12. Las respuestas de las que consta el expediente guardado en el Archivo del Museo Etnográfico son en su gran mayoría del Territorio de Misiones, el cual Ambrosetti había visitado previamente cuando aún no fuera director del Etnográfico. Para un mayor desarrollo de esta cuestión ver Ambrosetti, 2005; 2008.

13. El hecho "irregular" de que un expediente de la Dirección de Territorios Nacionales se encuentre en el fondo privado de Ambrosetti, dentro del Archivo del Museo, evidencia también cómo las vinculaciones personales se sobreponían a las mismas modalidades de orden institucional.

14. Respuesta del comisario de Apóstoles a la Gobernación de Misiones, por Circular $\mathrm{N}^{\circ} 555$, Misiones, 30 de agosto de 1915. AFDME, Carpeta Ambrosetti, Expediente "Trabajo en los territorios Nacionales a objeto de aumentar las colecciones", F. 9.

15. Respuesta del comisario de Santa Ana a la Gobernación de Misiones, por Circular $\mathrm{N}^{\circ} 555$, Misiones, 26 de agosto de 1915. AFDME, Expediente "Trabajo en los territorios Nacionales a objeto de aumentar las colecciones", F. 7. 
16. Respuesta del comisario de Corpus a la Gobernación de Misiones, por Circular $\mathrm{N}^{\circ} 555$, Misiones, 30 de agosto de 1915. AFDME, Carpeta Ambrosetti, Expediente "Trabajo en los territorios Nacionales a objeto de aumentar las colecciones", F. 13.

17. Del mismo modo que en la cita anterior o en la del comisario de Azara, Clementino Esquivel, se considera a Misiones como un territorio sin indígenas. Esto tiene su correlato con el discurso oficial, que indica que con la separación de las fronteras luego de la guerra de la Triple Alianza, los indígenas de ese territorio pasaron a ser parte del Paraguay y, por lo tanto, no se computaban como población argentina (Censo Nacional 1895)

18. Consideraciones del Ingeniero Francisco Fouilliand sobre la forma de obtener lo que el Museo desea y los lugares donde puede encontrarse adjunta en la respuesta de Soriano Romero al Director de Territorios Nacionales por Circular $N^{\circ} 82$, Posadas, 10 de agosto de 1915. AFDME, Fondo Ambrosetti, Expediente "Trabajo en los territorios Nacionales a objeto de aumentar las colecciones", F. 2-3.

19. Carta de Ambrosetti a Jorge Larrosa, Buenos Aires, junio 3 de 1913. AFDME, Carpeta Ambrosetti.

20. En la Memoria de 1908 se indicaba que la colección de doscientos cráneos se encontraba en proceso de arreglo y distribución, "para dejar preparada e instalada la Sección Antropológica, que actualmente cuenta con un local adecuado con siete armarios con vidrieras y cajones y dos mesas vidriadas. Memoria elevada por Ambrosetti a José N. Matienzo, decano de la Facultad de Filosofía y Letras, Buenos Aires, 10 de abril de 1908. AGFFyL, Caja B-5-10, Doc. 41.

21. A estos fines, Ambrosetti pedía autorización al decano para que el Dr. Robert LehmannNitsche estudiase el "cráneo humano fósil de Arrecifes, provincia de Buenos Aires" adquirido por la Facultad y catalogado con el № 1953. El resultado podría “publicarse en la Serie de Publicaciones Antropológicas que ya ha iniciado la Facultad". Nota de Ambrosetti a Jorge N. Matienzo, decano de la Facultad de Filosofía y Letras. Buenos Aires, 10 de diciembre de 1906. AGFFyL, Caja B-5-10, Doc. 37. Al año siguiente, el material antropológico había "aumentado con una serie de once esqueletos armados". Nuevamente, no se distinguía la antigüedad de los mismos. Memoria elevada por Ambrosetti a José N. Matienzo, decano de la FFyL, Buenos Aires, 14 de abril de 1909. AGFFyL, Caja B-5-10, Doc. 48.

22. Entre las adquisiciones del año se mencionaba "un esqueleto humano adulto y otro de un feto de siete meses para el curso de antropología". Memoria elevada por Ambrosetti a José N. Matienzo, decano de la FFyL, Buenos Aires, 14 de abril de 1909. AGFFyL, Caja B-5-10, Doc. 48. Otro ejemplo fue la donación de "un precioso cráneo de mujer microcéfala" obsequiado por el Dr. Alejandro Korn. AGFFyL, Caja B-5-12, Doc. 68.

23. Carta de Ambrosetti al decano de la Facultad de Filosofía y Letras, Buenos Aires, 24 de septiembre de 1907. AGFFyL. Caja B-5-10, Doc. 29.

24. Rostagno, 1969 [1911], p. 22.

25. Enrique Lynch Arribálzaga nació el 26 de agosto de 1856 en Buenos Aires (Argentina) y murió el 28 de junio de 1935. Junto a Eduardo L. Holmberg fundó la revista "El Naturalista Argentino" (1878), primera en su género. En 1881 viajó por primera vez a los Territorios Nacionales, como parte de una comisión comandaba por Jorge Luis Fontana. En 1887 fue nombrado subsecretario de Agricultura y más tarde delegado del mismo Ministerio para la reducción de indios. Unos años después se radicó definitivamente en el Chaco y en 1911 se convirtió en el primer director de la recién fundada reducción de Napalpí, cargo que mantendría hasta 1916 (Lynch Arribálzaga 1924; Viyeiro 2014).

26. Para un mayor desarrollo sobre la política de reducciones de indígenas en Argentina ver Musante (2013).

27. Para los antropólogos, las reducciones, misiones religiosas e ingenios azucareros brindaban la posibilidad de observar y estudiar a individuos de diferentes pueblos sin la necesidad de 
trasladarse de un lugar a otro, debido a la gran concentración de personas de diferentes grupos indígenas en un mismo espacio.

28. Carta de Ambrosetti a José N. Matienzo, decano de la Facultad de Filosofía y Letras, Buenos Aires, 2 de noviembre de 1907. AGFFyL. Caja B-5-10, Doc. 31.

29. También aparece mencionado el capitán Alberto Benavídez, quien donó varios objetos, aunque no disponemos aún de la suficiente información para detallar cómo se estableció el vínculo con este en particular.

30. Es muy importante señalar que el listado adjunto a la nota al decano -y que fuera transcrito en Pegoraro, 2009- que se encuentra en el AGFFyL no es un documento original, sino que se trata de una fotocopia de un manuscrito, que tampoco es posible confirmar si originalmente fuera escrito por Ambrosetti, dado que no condice con la carta mecanografiada. Por otro lado, la existencia de una correspondencia anterior (Carta de Pedro Cenóz a Ambrosetti, Formosa, 27 de junio de 1909. AFDME, Fondo de gestión institucional académico-administrativa, Serie historia de las colecciones, Legajo de colecciones № 17, Cenóz.) permite inferir que, posteriormente a la comunicación desde el decanato, Ambrosetti habría mantenido una correspondencia personal con Cenóz.

31. Carta de Pedro Cenóz a Ambrosetti, Formosa, 29 de octubre de 1909. AFDME, Fondo de gestión institucional académico-administrativa, Serie historia de las colecciones, Legajo de colecciones № 17, Cenóz.

32. Nota de Ambrosetti a José N. Matienzo, decano de la Facultad de Filosofía y Letras, Buenos Aires, 6 de noviembre de 1909. AGFFyL, Caja B-5-10, Doc. 72.

33. Carta de Ambrosetti a José N. Matienzo, decano de la Facultad de Filosofía y Letras, Buenos Aires, 29 de diciembre de 1909. AGFFyL. Caja B-5-10, Doc. 77.

34. Carta de Pedro Cenóz a Ambrosetti, Formosa, 27 de junio de 1909. AFDME, Fondo de gestión institucional académico-administrativa, Serie historia de las colecciones, Legajo de colecciones № 17, Cenóz.

35. Nota de Ambrosetti a José N. Matienzo, decano de la Facultad de Filosofía y Letras, Buenos Aires, 2 de noviembre de 1907. AGFFyL, Caja B-5-10, Doc. 31.

36. Según Chébez y Gasparri (2008), con sólo 13 años Ambrosetti fue presentado a Enrique Lynch Arribálzaga, en casa de Eduardo Holmberg. Que el vínculo personal entre ambos llevara tantos años, permite inferir que esto habilitaba a una comunicación sin demasiados reparos, lo que podría explicar lo "directo" del pedido.

37. En 1908 Lynch vendió al Museo Nacional de Buenos Aires una colección de 13 objetos de los indios tobas que fueron asentados en el catálogo con su nombre indígena (Pegoraro 2008).

38. Carta de Lynch Arribálzaga a Ambrosetti, Resistencia, 7 de diciembre de 1912. AFDME, Carpeta Ambrosetti.

39. El cacique Salarnek-alou, Juan el Raí (deformación de Juan el rey") o "Inglés" por el tono claro de su piel y su aspecto personal, era un gran cacique que comandaba gran cantidad de recursos, caciques menores y guerreros. Su poder ya era reconocido en 1870 por el coronel Napoleón Uriburu. Constituyó una amenaza para la ciudad de Resistencia, en conjunto con el cacique Cambá, a la que intentó desalentar el coronel Manuel Obligado en 1879. Hacia 1883, el gobernador de Chaco, Francisco Bosch, inició una nueva campaña contra el cacique, enfrentándose en Napalpí con la pérdida de gran cantidad de guerreros tobas. En 1884 el ministro Victorica embistió con tres regimientos de caballería, dos de infantería y tres buques de guerra, desbaratando a los principales grupos, matando caciques mayores y apresando guerreros. En combate con el Regimiento 12 de Caballería al mando de Obligado, el 17 de junio fue muerto el Inglés con tres de sus hijos, iniciándose el ciclo de "fin de los grandes cacicazgos". Antes de esto, el cacique había intentado deponer armas, pero no llegó a tiempo: "Se han presentado tres enviados del cacique Inglés salidos de los toldos antes que dicho cacique fuese atacado y los mandaba ponerse bajo las órdenes del gobierno y pedía que se les indicara a qué punto debía 
presentarse con su gente. Les he explicado lo que ha sucedido, ajeno a la voluntad del Gobierno, y los voy a despachar para que traigan esa tribu a Resistencia. Por estos mismos enviados sé que José Petiso se encuentra en la picada de los Campos del Cielo, a nuestro extremo izquierdo y se ofrecen ir hasta allí para tratar de reducirlo. Les doy también ese encargue y el plazo de todo el mes de Agosto próximo para que se presenten. La tribu de Petiso es la única que queda de los mocovíes que puede hacer daño a las poblaciones y por eso pongo tanto empeño para reducirla, pues los tobas, tan hostilizados, se han de ir al otro lado del Bermejo. Telegrama de Obligado al Ministro de Guerra y Marina, Reconquista, 29 de julio. Citado en Minnitti Morgan 2011, p. 42.

40. Carta de Lynch Arribálzaga a Ambrosetti, ciudad, 22 de diciembre de 1912. AFDME, Fondo de gestión institucional académico-administrativa, Serie historia de las colecciones, Legajo de colecciones № 60, Misión Lynch Arribálzaga.

41. Carta de Lynch Arribálzaga a Ambrosetti. Resistencia, 7 de mayo de 1913. Fondo de gestión institucional académico-administrativa, Serie historia de las colecciones, Legajo de colecciones № 60, Misiones Lynch Arribálzaga. AFDME.

42. Carta de Eduardito Holmberg a Ambrosetti, Ciudad, 20 de mayo de 1913. AFDME, Fondo de gestión institucional académico-administrativa, Serie historia de las colecciones, Legajo de colecciones № 52, Libia de Holmberg.

43. Carta de Lynch Arribálzaga a Ambrosetti. Resistencia, 9 de mayo de 1914. Fondo de gestión institucional académico-administrativa, Serie historia de las colecciones, Legajo de colecciones № 60, Misiones Lynch Arribálzaga. AFDME.

44. Además de los cráneos y huesos del territorio chaqueño que mencionamos, en las Memorias se señala el ingreso de cráneos procedentes de diferentes puntos del territorio (Buenos Aires, Chubut, Santa Fe, Río Negro, Tierra del Fuego, etc.) sin datos que permitan reconocer si se trata de cuerpos antiguos o contemporáneos.

45. De las referencias encontradas, en una se menciona "hija", mientras que en el resto se menciona "hijo". Aunque posiblemente solo se trate de un error, cumplimos en aclararlo.

46. Carta de Francisco M. Guerrero a Ambrosetti, sin mención de lugar, 2 de octubre de 1913. AFDME, Fondo de gestión institucional académico-administrativa, Serie historia de las colecciones, Legajo de colecciones № 18 , Guerrero.

47. Agustín Santiago, nacido en Casilda en 1892, escribió a pedido de su nieto Marcelo una de las escasas memorias de primera mano realizadas por un soldado partícipe de las campañas. La fuente aporta detalles del reclutamiento en la Gran Guardia y de la organización de fortines Yunká, Pilcomayo, Lagadik, Kilómetro 500, Las Lomitas, Pozo del Tigre y los puestos Guaruruú, Las Saladas, Manzanitas, Palo Blanco, Paso de los Tobas y Pirtane, donde en cada uno había 20 o 30 conscriptos armados y con una mula por persona. Los soldados entrenaban tiro y adiestraban a sus mulas para lograr docilidad (manuscrito reproducido en De Marco 2003).

48. De Marco 2003, p. 215.

49. De Marco 2003, pp. 216-217.

50. Cúndom 1962 citado en López Piacentini, 1979, pp. 91-93.

51. Cúndom 1962 citado en López Piacentini, 1979, pp. 96.

52. La tabla ha sido elaborada a partir de las siguientes fuentes: "Documentos de Colecciones", AFDME, Carpeta Ambrosetti; Memorias elevadas al decano de la Facultad de Filosofía y Letras entre 1904 y 1916, AFDME, Carpeta Ambrosetti y AGFFyL, Cajas B-5-10 y B-5-11. Debemos aclarar que la información vertida es solo la que hemos podido confrontar con las fuentes mencionadas, lo que implica que la misma pueda presentar algunos faltantes. En este sentido, en el caso de ciertos donantes o corresponsales mencionados en las Memorias de 1914, 1915 y 1916, como Jorge González Larrosa, Alberto Escalada, Salvador Debenedetti, Alfonso Najera, Cristóbal Hicken, Isaac Fernández Blanco, Sra. E. M. de Saint-Germain y Misión Sergei Geiman, no hemos podido identificar aún el detalle de la donación. Por otro lado, debemos aclarar que aunque el artículo se centra solo en el Chaco argentino, la tabla reúne también donaciones procedentes del Gran 
Chaco, incluyendo Paraguay y Bolivia. Por el contrario, no hemos incluido los ingresos de restos humanos de otras regiones del país, o aquellos que no se precisa su procedencia. Esta aclaración permite evidenciar que la cantidad de cráneos y esqueletos que ingresaron al Museo en el período examinado es mayor que la que aquí se consigna.

53. La mención institucional al cráneo de Carayá aparece en la Memoria de 1904 a 1911 con fecha 15 abril de 1911. Sin embargo, en la memoria del año de ingreso de 1911 no se indica el ingreso de este cráneo. En el documento de la donación, por su parte, se mencionan objetos calchaquíes y otros 100 objetos sin especificar, como colección recibida el 21 de abril de 1911 del Museo de Bellas Artes. No obstante, el número de catalogación coincide con 1911 como año de ingreso.

\section{ABSTRACTS}

In this article we analyze the entry of human remains to the Ethnographic Museum between 1904 and 1916,requested by his director Juan B. Ambrosetti to different persons and institutions. We will focus on those belonging to the remains of natives of the Argentine Gran Chaco, in the context of the military advance on this territory and the consequent dismantling of its ethnic organizations groups. We pointed that members of the army sent ethnographic objects and body remains to the Museum, upon a direct request from Ambrosetti to the Army. In particular we will examine the information about the remains that can could be identified: the indigenous chief Carayá, and Illirí; the latter was murdered being murdered in an ambush and sent directly to the Museum once the flesh of his body had been removed (from the bones). Those cases allow us to concentrate on the nexus between the anthropological science and the military campaigns, framed by the territorial advance of the state at the beginning of the twentieth century.

En este artículo analizamos el ingreso de restos humanos al Museo Etnográfico entre 1904 y 1916, por pedido de su director Juan B. Ambrosetti a diferentes personas e instituciones. Nos centramos en aquellos pertenecientes a indígenas del Gran Chaco argentino, en el contexto del avance militar sobre ese territorio y la consecuente desarticulación de sus pueblos originarios. En este sentido, destacamos cómo miembros del mismo Ejército enviaron objetos etnográficos y restos óseos al Museo, respondiendo a una solicitud directa de Ambrosetti a dicha fuerza armada. En particular, examinamos algunos datos acerca de los únicos de estos restos identificados, el cacique Carayá y el cacique Illirí, este último asesinado en una emboscada y enviado directamente al Museo una vez descarnado. Los casos permiten poner de relieve el vínculo entre la ciencia antropológica y las campañas militares, en el marco de la acción de avance territorial del Estado-nación a principios del siglo XX.

\section{INDEX}

Keywords: Human remains, indigenous chiefs, campaigns to Gran Chaco, Juan B. Ambrosetti; Ethnographic Museum.

Palabras claves: Restos humanos, caciques, campañas al Chaco, Juan B. Ambrosetti, Museo Etnográfico 


\section{AUTHORS}

\section{SANDRA TOLOSA}

Universidad de Buenos Aires, Facultad de Filosofía y Letras, Argentina

Correo electrónico: cahsandra@gmail.com

\section{LENA DÁVILA}

Universidad de Buenos Aires, Facultad de Filosofía y Letras; Consejo Nacional de Investigaciones Científicas y Técnicas, UBACyT 20020130100447BA dirigido por la Dra. Cecilia Hidalgo, Argentina Correo electrónico: lena.davila@yahoo.com.ar 